\title{
ANÁLISE SOCIOAMBIENTAL DO PROCESSO DE IMPLANTACÃO/OPERAÇÃO DE USINAS EÓLICAS NA RESERVA DE DESENVOLVIMENTO SUSTENTÁVEL ESTADUAL PONTA DO TUBARÃO, MACAU/GUAMARÉ, RIO GRANDE DO NORTE - BRASIL
}

\author{
Dweynny Rodrigues Filgueira Gê \\ Universidade do Estado do Rio Grande do Norte \\ dweynny@yahoo.com.br \\ Rodrigo Guimarães de Carvalho \\ Universidade do Estado do Rio Grande do Norte \\ rodrigo.ufc@gmail.com \\ Christian Brannstrom \\ Texas A\&M University \\ cbrannst@geos.tamu.edu \\ Adryane Gorayeb \\ Universidade Federal do Ceará \\ adryanegorayeb@yahoo.com.br \\ Márcia Regina Farias da Silva \\ Universidade do Estado do Rio Grande do Norte \\ mreginafarias@hotmail.com
}

\section{RESUMO}

Os parques eólicos vêm sendo instalados de forma rápida e continua no Nordeste do Brasil, principalmente no litoral devido a melhor qualidade dos ventos. Muitos impactos socioambientais vêm sendo relatados na literatura científica, com destaque para instalação desses empreendimentos em unidades de conservação. Essa pesquisa buscou compreender o processo de instalação/operação de três parques eólicos em Reserva de Desenvolvimento Sustentável (RDS) situada no litoral do Rio Grande do Norte. A metodologia consistiu na coleta de dados a partir de documentos oficiais e registro de reuniões do conselho gestor, entrevistas com atores locais e pesquisa participante em seminário integrado de comunidades tradicionais sobre os impactos socioambientais dos parques. Verificou-se que o processo de licenciamento ambiental dos três parques eólicos ocorreu sem que houvesse discussão e deliberação favorável do conselho gestor da RDS. Os empreendimentos causaram impactos ambientais e conflitos socioambientais, afetando o meio ambiente e os modos de vida tradicionais. Concluiu-se que na RDSEPT, mesmo com forte governança local, os mecanismos de discussão e deliberação não foram respeitados quando da entrada de empreendimentos eólicos e os impactos socioambientais foram ampliados sob a tutela do órgão licenciador e gestor de unidades de conservação.

Palavras-chave: Energia. Recursos Renováveis. Meio Ambiente. Conflitos.

\section{SOCIO-ENVIRONMENTAL ANALYSIS OF THE PROCESS OF IMPLANTATION/OPERATION OF WIND FARMS IN THE RESERVA DE DESENVOLVIMENTO SUSTENTÁVEL ESTADUAL PONTA DO TUBARÃO, MACAU/GUAMARÉ, RIO GRANDE DO NORTE - BRAZIL}

\begin{abstract}
Wind farms are being installed quickly and continue in Northeast Brazil, mainly on the coast due to better wind quality. Many socioenvironmental impacts have been reported in the scientific literature, with emphasis on the installation of these projects in protected areas. This research sought to understand the installation / operation process of three wind farms in a Sustainable Development Reserve (RDS) located on the coast of Rio Grande do Norte. The methodology consisted of collecting data from official documents and recording management board meetings, interviews with local actors and participating research in an integrated seminar of traditional communities on the socio-environmental impacts of the parks. It was found that the process of environmental licensing of the three wind farms occurred without there being a favorable discussion and deliberation by the RDS management council. The ventures have caused environmental impacts and socioenvironmental conflicts, affecting the environment and traditional ways of life. It was
\end{abstract}


Análise socioambiental do processo de implantação/operação de usinas eólicas na Reserva de Desenvolvimento Sustentável Estadual Ponta do Tubarão, Macau/Guamaré, Rio Grande do Norte - Brasil
Dweynny R. Filgueira Gê

Rodrigo Guimarães de Carvalho Christian Brannstrom

Adryane G. Nogueira Caetano Márcia Regina Farias da Silva

concluded that in RDSEPT, even with strong local governance, the mechanisms of discussion and deliberation were not respected when the entry of wind farms and the socioenvironmental impacts were expanded under the tutelage of the licensing agency and manager of conservation units.

Keywords: Energy. Renewable resources. Environment. Conflicts.

\section{INTRODUÇÃO}

Em 2017, aproximadamente $66,8 \%$ da produção mundial de eletricidade está relacionada diretamente com a matriz fóssil (IEA, 2017). É sabido que o emprego de fontes fósseis para produção de energia vem causando impactos globais como emissão de gases, principalmente o dióxido de carbono (CO2), o metano ( $\mathrm{CH} 4)$ e o óxido nitroso (NOx) que contribuem para o efeito estufa e consequente aquecimento global (MOREIRA et al., 2013).

Assim, as fontes energéticas renováveis surgem como alternativa à sociedade no tocante ao atendimento da demanda por energia de qualidade, segurança na disponibilidade de eletricidade, além do estabelecimento de sistema de energia de baixo consumo de carbono com a finalidade de reduzir a dependência dos combustíveis fósseis finitos, diminuindo os danos ambientais (MARTINS et al., 2008; GEIBLER et al., 2013; DAl et al., 2015).

A energia eólica tem lugar de destaque no cenário atual de mudanças climáticas (ARVESEN; HERTWICH, 2012) e sua utilização cresceu exponencialmente nas últimas décadas, principalmente nos últimos 20 anos, onde inúmeros países realizaram investimentos no setor, com a finalidade de reduzir emissões de carbono. Na década de 1990 do século XX não existia mais que $15 \mathrm{GW}$ instalados de potência eólica ao redor do mundo, em 2019 esse número atingiu 621,42 GW (KALDELLIS et al., 2016; GWEC, 2019).

De fato, a produção de energia eólica está envolvida em um discurso de sustentabilidade. Todavia, existem riscos envolvidos desde o processo de instalação ao de geração. Portanto, o licenciamento ambiental e estudos de viabilidade econômica e ambiental devem abranger fatores desde impactos a avifauna, às respostas sociais ao arrendamento de terras e utilização de áreas sensíveis para instalação de parques eólicos (FREITAS, 2016).

Meireles (2011) corrobora o discurso de Freitas (2016) ao relatar que muitas áreas que apresentam grande potencial eólico também possuem comunidades em seu entorno que sofrem inúmeros impactos durante a fase de montagem, construção e operação dos parques eólicos, além de impactos ao meio ambiente, dentre os quais destacam-se: impactos visuais e sonoros, impactos sobre a avifauna e outros tipos de impactos sobre o ambiente ecológico como desmatamento e soterramento de dunas fixas, introdução de material sedimentar para compactação do solo, fixação de dunas móveis (MEIRELES, 2011; KALDELLIS et al., 2016;).

A percepção de possível impacto ambiental e a alteração das paisagens têm criado inúmeros conflitos entre vários atores sociais inseridos em áreas de implantação de parques eólicos. Surgem movimentos de resistência à implantação de parques eólicos em determinadas localidades, geralmente através de lideranças locais ou organizações sociais (HOFSTAETTER; PESSOA, 2015). No Nordeste brasileiro vários estudos confirmam a existência de conflitos socioambientais advindos da instalação e operação de empreendimentos eólicos (BRANNSTROM et al., 2017; BRANNSTROM et al., 2018; GORAYEB et al., 2018; DANTAS et al., 2019; FRATE et al., 2019; Gê et al., 2019).

Aspectos geográficos como relevo, clima e localização favorecem ao aproveitamento eólico brasileiro, com vistas principalmente para região Nordeste, onde, segundo o Atlas do Potencial Eólico Brasileiro (AMARANTE, 2001), as médias anuais das velocidades dos ventos superam $6 \mathrm{~m} / \mathrm{s}$ a $50 \mathrm{~m}$ de altura, comprovando a viabilidade da implantação quanto as condições geográficas e técnicas. Em atualização do referido atlas, foram realizadas simulações em 2013, publicada em 2017, onde são apresentadas médias de velocidades anuais dos ventos no Brasil nas alturas de $30 \mathrm{~m}, 50 \mathrm{~m}, 80 \mathrm{~m}, 100 \mathrm{~m}, 120 \mathrm{~m}, 150 \mathrm{~m}$ e $200 \mathrm{~m}$ metros. Verifica-se que a região Nordeste ratifica o potencial, principalmente, em estados como Rio Grande do Norte e Ceará, onde a aptidão para a produção de energia eólica é confirmada (CEPEL, 2017).

É importante salientar que os Atlas de Energia Eólica do Brasil $(2001,2017)$ apresentam a localização da qualidade dos ventos, sem o mínimo detalhe sobre gestão do território e dos recursos naturais, além de populações/comunidades tradicionais que habitam essas regiões. $O$ atlas elaborado por órgão

$\begin{array}{llllll}\text { Caminhos de Geografia } & \text { Uberlândia-MG } & \text { v. 23, n. } 85 & \text { fev./2022 } & \text { p.115-136 } & \text { Página } 116\end{array}$


Análise socioambiental do processo de implantação/operação de usinas eólicas na Reserva de Desenvolvimento Sustentável Estadual Ponta do Tubarão, Macau/Guamaré, Rio Grande do Norte - Brasil
Dweynny R. Filgueira Gê

Rodrigo Guimarães de Carvalho Christian Brannstrom Adryane G. Nogueira Caetano Márcia Regina Farias da Silva

governamental apresenta a energia eólica como alternativa energética com possibilidade de implementação simplificada (AMARANTE, 2001).

No Rio Grande do Norte estudos apontam a viabilidade técnica e econômica da implantação de turbinas eólicas para produção de energia elétrica, o que é evidenciado pela maior produção eólica do Brasil, com 157 parques em operação e geração de 4,22 GW (ANEEL, 2020). Os Parques Eólicos têm sido implantados, em grande parte, na zona costeira (Amarante, 2003), verifica-se que aproximadamente $58 \%$ dos aerogeradores instalados no RN estão situados até $25 \mathrm{Km}$ de distância da linha da costa (BRANNSTROM et al., 2018) em paisagens com a presença de comunidades de pescadores e agricultores de subsistência, com a possibilidade de descaracterizar e afetar as tradições e identidade dessas comunidades, como também influenciar atividades vinculadas ao turismo (HOFSTAETTER; PESSOA, 2015).

O litoral setentrional do Rio Grande do Norte possui 244 km de extensão e possuía até 2017 apenas uma Unidade de Conservação (UC), a Reserva de Desenvolvimento Sustentável Estadual Ponta do Tubarão (RDSEPT) criada a partir da promulgação da lei estadual 8.349 de 18 de julho de 2003 (NOBRE, 2005). Uma nova UC foi criada em 2018, a Área de Proteção Ambiental das Dunas do Rosado, por meio do Decreto estadual 27.695 de fevereiro de 2018. A área da RDSEPT está inserida no mapa de áreas com potencial para geração de eletricidade por meio da energia eólica (AMARANTE, 2003), isso já se comprova com a instalação de parques eólicos na área e entorno.

Portanto, o presente trabalho teve como objetivo geral estudar a instalação dos parques eólicos na RDSEPT no período de 2006 a 2012. Foram objetivos específicos: analisar como foi o processo de discussão e decisão sobre a implantação dos parques eólicos no âmbito do Conselho Gestor deliberativo da RDSEPT; identificar os conflitos socioambientais e impactos da instalação e operação dos parques; e analisar as alternativas locacionais para a implantação dos parques na RDSEPT.

\section{ÁREA DE ESTUDO}

A RSDEPT está localizada no Estado do Rio Grande do Norte, inserida no território de 02 municípios, Macau e Guamaré, além de se estender por $2 \mathrm{~km}$ no mar territorial brasileiro. Ocupa área total de, aproximadamente, 12.940 hectares (Figura 1) (MATTOS et al., 2012).

A área da reserva é composta por 12 comunidades, a saber: em Macau: Diogo Lopes, Sertãozinho, Barreiras, Chico Martins, Cacimba da Baixa, Baixa do Grito, Varjota, Canto da Umburana e Pau Feito. Em Guamaré: Mangue Seco I, Mangue Seco II e Lagoa Doce. Os habitantes da reserva somam aproximadamente 10.000 pessoas (RIO GRANDE DO NORTE, 2018), com destaque para Diogo Lopes, Sertãozinho e Barreiras que são as comunidades com maior quantidade populacional, representando aproximadamente $80 \%$ da população total.

A RDSEPT está situada entre os biomas caatinga e marinho e apresenta unidades geoecológicas como praia, planície de maré com manguezal, dunas, tabuleiro costeiro com mata de caatinga e ambiente marinho. Essas unidades são habitadas por populações que fazem uso da atividade pesqueira tradicional (RIO GRANDE DO NORTE, 2018).

O litoral setentrional do Rio Grande do Norte, principalmente na região onde encontra-se a RDSEPT, do ponto de vista geológico regional, apresenta características sedimentares com influência da Bacia Potiguar, com duas formações relevantes para a economia regional: Jandaíra (calcário) e Açu (arenito), essa característica justifica a presença da Petrobras - Petróleo Brasileiro S.A. na área terrestre e marinha da reserva e no entorno. No tocante as características de relevo, a RDSEPT apresenta como formas mais marcantes a Restinga ou "Costa", como é conhecida a nível local, a planície de Maré, os Campos de Dunas e o Tabuleiro Costeiro. Vale salientar que o relevo da RDSEPT possui grande relação com os aspectos geológicos, ou seja, os processos atuantes e a estrutura sedimentar modelam as formas do relevo local, apresentando mudanças muito rápidas em curto espaço de tempo, considerando o tempo geológico (idem).

Com relação aos aspectos climáticos a área da reserva possui um clima semiárido, com chuvas irregulares, predomínio de estação seca com 7 a 8 meses de duração (junho a janeiro) e estação chuvosa de fevereiro a maio. A precipitação anual na região é inferior $750 \mathrm{~mm}$ e entre agosto e dezembro ocorre o período de estiagem mais rigoroso, onde as precipitações médias não atingem a marca de $10 \mathrm{~mm}$ (MAMERI, 2011). 
Análise socioambiental do processo de implantação/operação de usinas eólicas na Reserva de Desenvolvimento Sustentável Estadual Ponta do Tubarão, Macau/Guamaré, Rio Grande do Norte - Brasil
Dweynny R. Filgueira Gê Rodrigo Guimarães de Carvalho Christian Brannstrom Adryane G. Nogueira Caetano Márcia Regina Farias da Silva

Figura 1 - Macau/Guamaré (RN): Localização da RDSEPT, 2018.

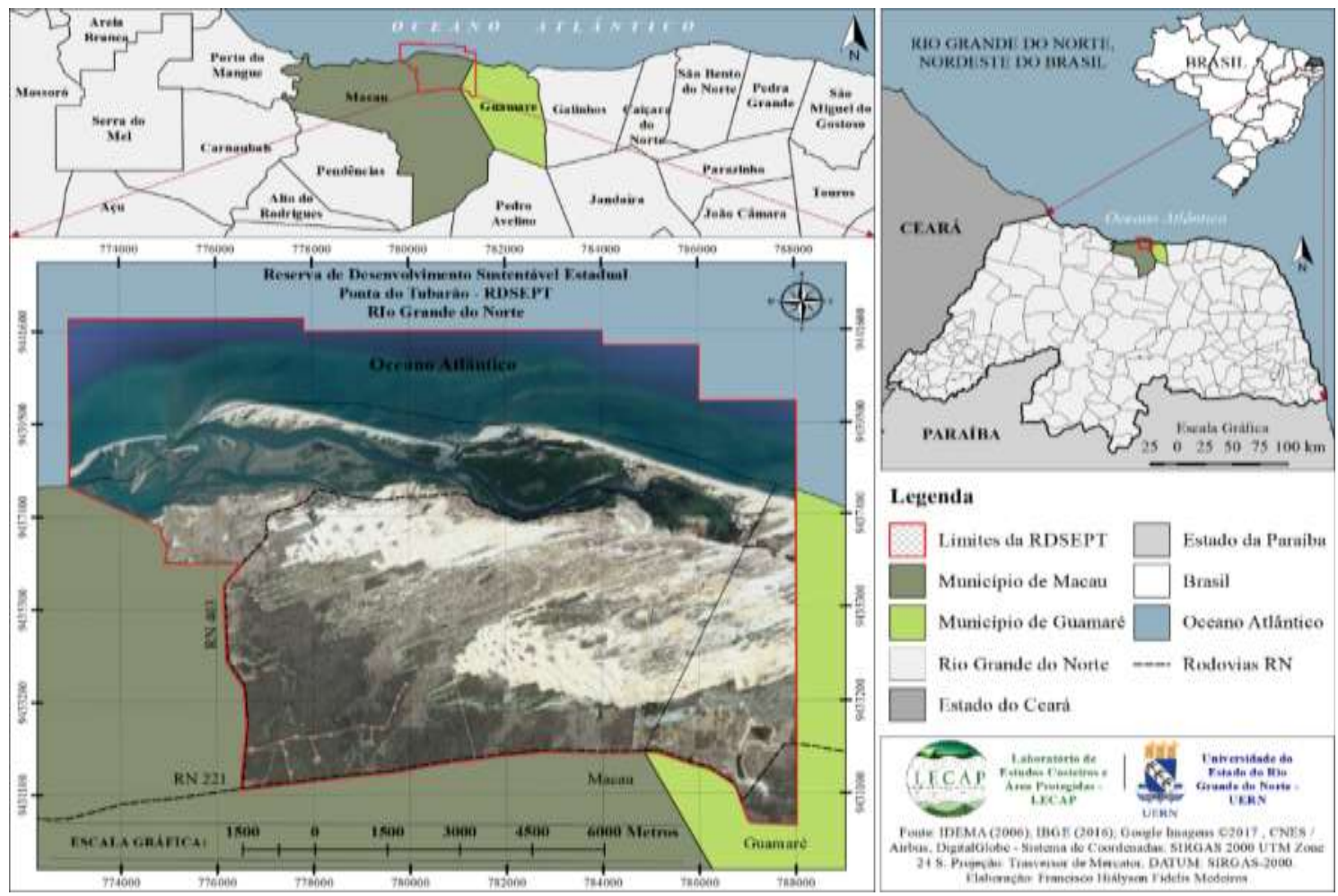

Fonte: GÊ, 2018

A RDSEPT, de acordo com o Atlas do Potencial Eólico do RN, está inserida em área de aproveitamento eólico (AMARANTE, 2003), com isso, já se constata a instalação de 3 (três) parques eólicos no interior da reserva: Miassaba II, Miassaba III e Alegria II, além de 1 (um) parque eólico em seu entorno: Mangue Seco V (Figura 2).

O parque eólico Miassaba III entrou em operação no dia 01 de fevereiro de 2014 com capacidade de geração de 68,47 MW (ANEEL, 2018). O parque está localizado na área de tabuleiro da RDSEPT e é composto por 41 aerogeradores, a extensão dos acessos para o mesmo é de 21,5 km e durante sua construção foi utilizado $10.800 \mathrm{~m}^{3}$ de concreto para as fundações dos aerogeradores (DOIS A ENGENHARIA, 2018).

O parque eólico Alegria II é responsável pela produção de 100,65 MW, sendo um dos maiores parques de produção no Rio Grande do Norte. O empreendimento eólico entrou em operação no dia 30 de dezembro de 2012, os aerogeradores do parque estão localizados na área de dunas da RDSEPT (ANEEL, 2018) e são 61 aerogeradores instalados (THE WIND POWER, 2017a).

Com relação ao parque eólico de Miassaba II são produzidos 14,4 MW e a data de entrada em operação foi dia 22 de dezembro de 2011, o parque está localizado em área de restinga com grande proximidade do mar (ANEEL, 2018). O parque possui 9 aerogeradores com potência de 1,6 MW, diâmetro de $82,5 \mathrm{~m}$ e altura de 80m (THE WIND POWER, 2017b).

Figura 2 - Macau/Guamaré (RN): Localização dos Parques eólicos instalados na RDSEPT. 
Análise socioambiental do processo de implantação/operação de usinas eólicas na Reserva de Desenvolvimento Sustentável Estadual Ponta do Tubarão, Macau/Guamaré, Rio Grande do Norte - Brasil
Dweynny R. Filgueira Gê Rodrigo Guimarães de Carvalho Christian Brannstrom Adryane G. Nogueira Caetano Márcia Regina Farias da Silva

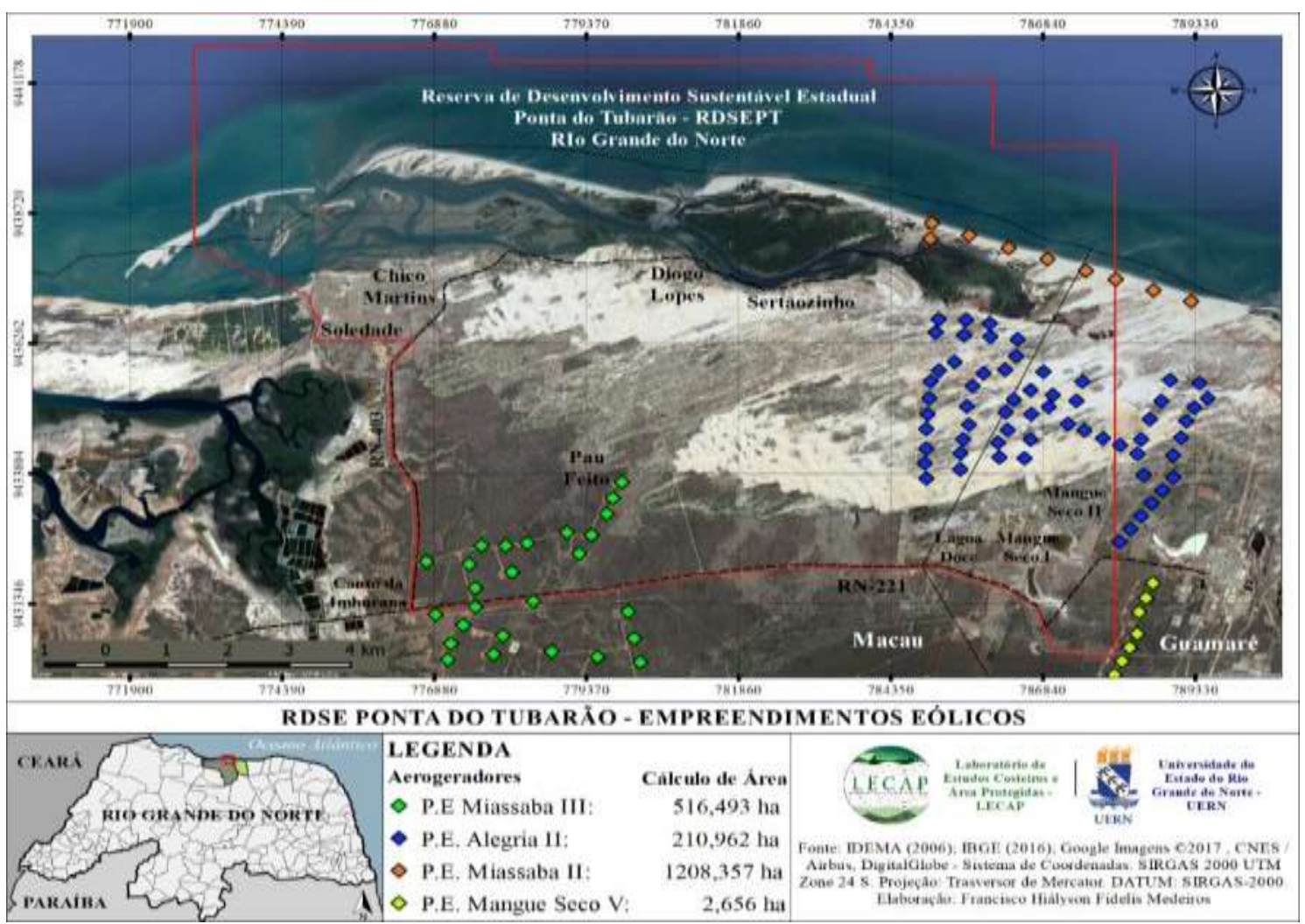

Fonte: GÊ, 2018.

\section{MATERIAIS E MÉTODOS}

\section{Caracterização da pesquisa}

A presente investigação possui abordagem qualitativa, onde a análise e o estudo do mundo empírico no ambiente natural configuram-se como fundamento, além da valorização do contato direto do pesquisador com o ambiente e o problema da situação estudada, além de permitir avaliação e análise crítica de fenômenos sociais e ambientais por meio da construção social dos fenômenos verificados e a contextualização histórica (GODOY, 1995; RICHARDSON, 2008).

Quanto aos procedimentos pesquisa apresentada é: bibliográfica, produzida por meio de livros e artigos científicos e tem importância para o levantamento de informações sobre a temática estudada (LAKATOS; MARCONI, 2001); documental, semelhante a pesquisa bibliográfica com a diferença que a documental utiliza, geralmente, materiais que não receberam tratamento analítico, possibilitando reelaboração de acordo com os objetivos da pesquisa (GIL, 1999); de campo, onde permite ao pesquisador presenciar a interação das pessoas em situações diferentes e realizar constatações e indagações sobre as motivações e ações presenciadas; e pesquisa participante em que o pesquisador torna-se componente da situação estudada, interagindo com os sujeitos, com a finalidade de vivenciar o cotidiano para observar e analisar o que significar partilhar aquela situação. Para complementar o embasamento da pesquisa em questão, o observador participante combina os fatos colhidos durante a observação com a análise dos documentos, ou seja, todo material teórico documental que sustenta os argumentos da investigação (ALVESMAZZOTTI; GEWANDSZNAJDER, 1999).

\section{Etapas da pesquisa}

A pesquisa pode ser dividida em 4 etapas: 1) Análise de material textual (bibliográfico); 2) Análise de atas de reunião e documento do Conselho Gestor que trata sobre considerações aos projetos de parques eólicos em licenciamento na RDSEPT; 3) Participação em Seminário sobre impactos sociais e ambientais dos parques eólicos no Nordeste Brasileiro 4) Visitas a campo para aplicação de entrevistas e coleta de dados. Ressalta-se que o estudo foi formalmente aprovado pelo Conselho Gestor da RDSEPT por meio

$\begin{array}{llllll}\text { Caminhos de Geografia } & \text { Uberlândia-MG } & \text { v. 23, n. } 85 & \text { fev./2022 } & \text { p. 115-136 } & \text { Página } 119\end{array}$


Análise socioambiental do processo de implantação/operação de usinas eólicas na Reserva de Desenvolvimento Sustentável Estadual Ponta do Tubarão, Macau/Guamaré, Rio Grande do Norte - Brasil
Dweynny R. Filgueira Gê

Rodrigo Guimarães de Carvalho Christian Brannstrom

Adryane G. Nogueira Caetano Márcia Regina Farias da Silva

do Núcleo de Unidades de Conservação (NUC) do Instituto de Desenvolvimento Sustentável e Meio Ambiente do Rio Grande do Norte (IDEMA) e os documentos obtidos (atas de reunião) foram cedidos pelo referido Conselho.

Primeiramente, a pesquisa tem como base de sustentação o levantamento de dados secundários, por meio da pesquisa em livros, sites oficiais de instituições públicas e privadas, artigos de periódicos nacionais e internacionais, dissertações, relatórios técnicos e teses pertinentes ao assunto em questão. O levantamento bibliográfico e documental foi contínuo e dinâmico, pois não se encerram devido a feição variável da temática envolvendo energias renováveis.

$\mathrm{Na}$ segunda etapa da pesquisa foram apreciadas/analisadas 58 atas de reuniões extraordinárias e ordinárias do Conselho Gestor da RDSEPT e o documento "Considerações sobre os projetos de parques eólicos para a área da Reserva de Desenvolvimento Sustentável Estadual Ponta do Tubarão (RDSEPT) em processo de licenciamento ambiental, 2009.". As atas de reuniões analisadas foram de reuniões realizadas entre maio de 2006 a dezembro de 2012 e teve como objetivo verificar e analisar o processo de discussão relacionada à autorização de implantação dos parques eólicos na Reserva. A análise documental das atas foi realizada por meio da leitura e sistematização de falas que tratavam de pontos relacionados à instalação de energia eólica na Reserva. Vale salientar que nem todas as atas tratam da questão da implantação dos parques eólicos e estas não foram consideradas para este estudo. Outro documento importante confeccionado pelo Conselho Gestor foi analisado durante a pesquisa: "Considerações sobre os projetos de parques eólicos para a área da Reserva de Desenvolvimento Sustentável Estadual Ponta do Tubarão (RDSEPT) em processo de licenciamento ambiental”, datado em 2009, com 10 páginas e que trata dos impactos dos parques eólicos planejados para implantação na área da reserva.

$\mathrm{Na}$ terceira etapa foi realizada pesquisa participante entre os dias 22 e 24 de setembro de 2017, no município de Juazeiro, Estado da Bahia, na sede do Instituto Regional da Pequena Agropecuária Apropriada (IRPAA), onde foi realizado "Seminário sobre impactos sociais e ambientais dos parques eólicos no Nordeste Brasileiro". O evento teve programação focada em reflexões sobre a situação de invisibilidade dos indivíduos de comunidades no nordeste do Brasil; sistematização de mapas de conflitos, impactos e resistência das comunidades e avaliação da política energética com cenários e perspectivas da energia eólica, tendo como base as experiências dos participantes que em sua maioria eram representantes de comunidades tradicionais afetadas pela energia eólica. Durante todo evento foram realizadas dinâmicas em grupos com no mínimo uma hora de duração e essas foram registradas com auxílio de gravador.

O seminário teve 51 participantes, representantes de instituições e de comunidades, de 6 estados da região nordeste, a saber: Bahia, Ceará, Pernambuco, Maranhão, Rio Grande do Norte (inclusive representantes da RDSEPT) e Paraíba. O evento produziu documento de referência, no tocante ao bem comum e Direito Humano, para a nortear contraproposta das comunidades relacionada ao modelo vigente de construção e operação de empreendimentos eólicos (Figura 3 A e B).

Figura 3 - Juazeiro (BA): (A) Cartaz do Seminário sobre impactos sociais e ambientais dos parques eólicos no Nordeste Brasileiro. (B) Participação do pesquisador em dinâmica com grupo da RDSEPT durante as atividades do seminário, 2017. 
Análise socioambiental do processo de implantação/operação de usinas eólicas na Reserva de Desenvolvimento Sustentável Estadual Ponta do Tubarão, Macau/Guamaré, Rio Grande do Norte - Brasil
Dweynny R. Filgueira Gê

Rodrigo Guimarães de Carvalho Christian Brannstrom Adryane G. Nogueira Caetano Márcia Regina Farias da Silva
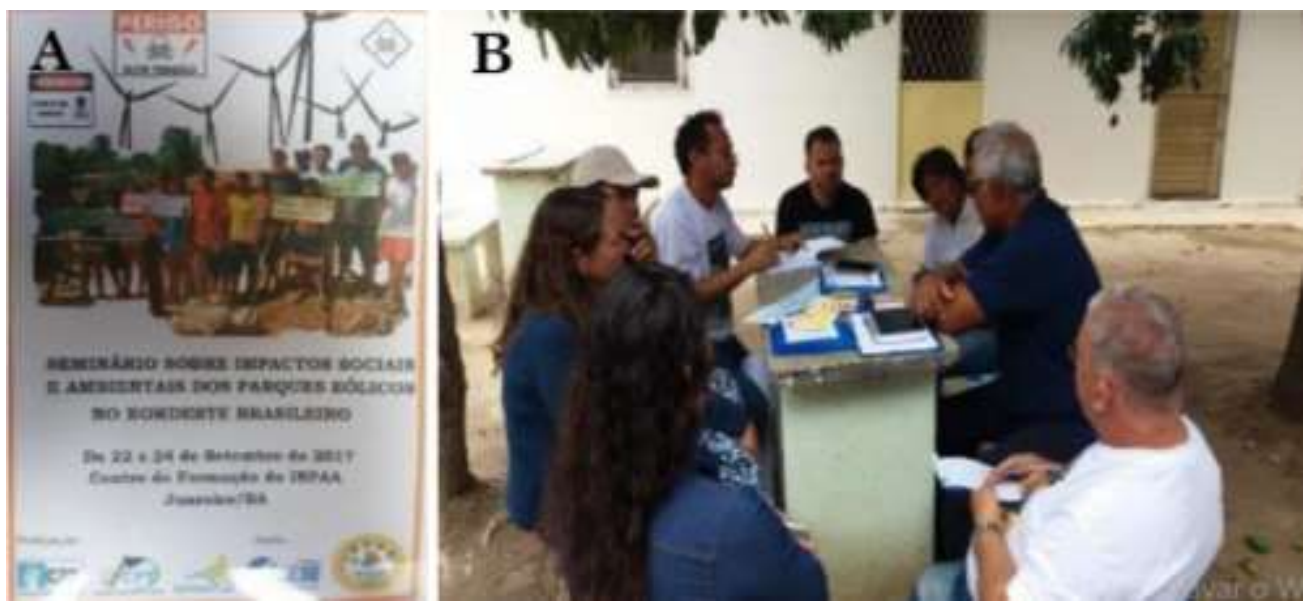

Fonte: Autor, 2017.

A quarta etapa da pesquisa foi realizada com visitas a campo, entre os anos de 2016 e 2017, nas áreas que estão instalados os parques eólicos, por exemplo, área de dunas, tabuleiro e praia. Foram realizadas entrevistas informais com moradores das comunidades e 04 entrevistas formais estruturadas com questões abertas direcionadas a moradores que residiam na RDSEPT há mais de 10 anos e que de forma direta ou indireta estiveram envolvidos no processo de discussão sobre a implantação dos empreendimentos eólicos na RDSEPT. As entrevistas foram estruturadas com questões abertas que versaram sobre: participação e atuação no Conselho Gestor, conhecimento sobre a implantação de energia eólica na RDSEPT, impactos positivos e negativos da implantação e aceitação de novos empreendimentos na área da reserva. Por meio de Termo de Consentimento Livre e Esclarecido (TCLE) foi assegurado o sigilo e proteção das informações fornecidas, além da autorização para divulgação dos dados/resultados da pesquisa. As entrevistas foram gravadas para posterior transcrição com a finalidade de assegurar a fidelidade das informações coletadas. Notas de campo foram organizadas de acordo com os principais temas. $\mathrm{O}$ trabalho de campo participativo forneceu conhecimento para analisar com maior profundidade documentos como as atas de reuniões do Conselho Gestor.

Nesse sentido, a identificação dos impactos socioambientais da instalação e operação dos parques eólicos na RDSEPT teve como método a pesquisa documental contemplando a avaliação das atas de reuniões do Conselho Gestor e do documento "Considerações sobre os projetos de parques eólicos para a área da Reserva de Desenvolvimento Sustentável Estadual Ponta do Tubarão (RDSEPT) em processo de licenciamento ambiental, 2009." Além disso, durante o trabalho de campo, nas entrevistas, foram realizados questionamentos acerca dos impactos socioambientais causados pelos empreendimentos eólicos e, assim, estabelecida a discussão do tema com a literatura nacional e internacional.

\section{RESULTADOS E DISCUSSÃO}

\section{Análise das atas de reunião do conselho gestor da RDSEPT}

Antes da análise das atas de reuniões é importante frisar que o processo de licenciamento dos empreendimentos eólicos na área da RDSEPT ocorreu conforme os preceitos da Resolução CONAMA n 279 de 27 de junho de 2001 que estabeleceu procedimento simplificado para o licenciamento ambiental, com prazo máximo de sessenta dias de tramitação, dos empreendimentos com impacto ambiental de pequeno porte, necessários ao incremento da oferta de energia elétrica no País. No entanto, por se tratar de uma Unidade de Conservação a RDSEPT tem amparo legal por meio da Lei n ${ }^{\circ} 9.985$ de 18 de julho de 2000, que cria o Sistema Nacional de Unidades de Conservação e prevê no artigo 20, parágrafo $4^{\circ}$ que a "Reserva de Desenvolvimento Sustentável será gerida por um Conselho Deliberativo, presidido pelo órgão responsável por sua administração e constituído por representantes de órgãos públicos, de organizações da sociedade civil e das populações tradicionais residentes na área, conforme se dispuser em regulamento e no ato de criação da unidade."

Nesse sentido, a análise das atas revela que o Órgão Gestor da RDSEPT, não respeitou as decisões do Conselho Gestor, uma vez que em nenhum momento foi verificada deliberação com aprovação para

$\begin{array}{lllll}\text { Caminhos de Geografia } & \text { Uberlândia-MG } & \text { v. 23, n. 85 } & \text { fev./2022 } & \text { p. 115-136 Página } 121\end{array}$


Análise socioambiental do processo de implantação/operação de usinas eólicas na Reserva de Desenvolvimento Sustentável Estadual Ponta do Tubarão, Macau/Guamaré, Rio Grande do Norte - Brasil
Dweynny R. Filgueira Gê

Rodrigo Guimarães de Carvalho Christian Brannstrom

Adryane G. Nogueira Caetano Márcia Regina Farias da Silva

instalação e operação dos parques eólicos na área. Houve oportunidades que conselheiros(as) insistiram em afirmar que o Conselho Gestor não deliberou sobre o assunto e outras ocasiões em que o IDEMA tentou aprovar a temática, porém em nenhuma ata analisada nessa pesquisa foi verificada votação sobre a instalação das eólicas na Reserva. Deve ser destacado que o Órgão Gestor da RDSEPT é o mesmo que licencia os parques eólicos. Na época de instalação dos três parques na reserva (entre 2010 e 2012), esta era a única unidade de conservação existente nos $244 \mathrm{~km}$ de extensão do litoral setentrional do Rio Grande do Norte, havendo, portanto, muitas áreas adjacentes que não eram legalmente protegidas como Ucs.

A primeira ata que apresenta a temática de energia eólica é a 57 a reunião ordinária, realizada em 20 de junho de 2008, quando o IDEMA, informou que uma empresa procurou o instituto para saber sobre a possibilidade de implantação de parques eólicos na área da RDSEPT e a mesma foi informada que o processo teria que ser apresentado e aprovado pela plenária do Conselho Gestor. Na 58 Extraordinária, realizada no dia 20 de julho de 2008 foi feita denuncia por conselheiros(as), que havia especulação imobiliária em terrenos da RDSEPT para instalação de aerogeradores. Percebe-se que existem interesses na instalação de parques eólicos na área da RDSEPT e o Órgão Gestor da Reserva surge com a temática em meados de 2008.

Inicialmente os(as) conselheiros(as) não possuíam posição definida com relação a implantação e instalação dos parques eólicos na área da RDSEPT, pois se tratava de um empreendimento novo e com um discurso de sustentabilidade, o que pode ser caracterizado na literatura como "land grabbing" ou "green grabbing" (FAIRHEAD et al., 2012) termos que representam o movimento de busca por terras ou pelo verde global utilizando, para isso, o discurso da sustentabilidade.

Em meados de 2009, o assunto voltou a ser discutido na plenária do Conselho Gestor na $71^{\text {a }}$ reunião ordinária, realizada em 02 de junho de 2009. O IDEMA em resposta ao(à) representante da Comissão de Justiça e Paz (CJP) relatou que, até o momento, não existiam processos de licenciamentos relacionados à energia eólica na área da RDSEPT. No entanto, em 20 de agosto de 2009, durante a 37ạ reunião ordinária é criada de maneira repentina uma comissão para analisar projetos de energia eólica na área da RDSEPT. Já em 25 de setembro de 2009 na 39ª reunião extraordinária é realizada a apresentação de vários projetos de energia eólica na área da Reserva.

Percebe-se que em um período de 3 meses a situação relacionada aos parques eólicos muda completamente, pois em junho de 2009 não existiam, segundo o IDEMA, processos de licenciamento de eólicas na RDSEPT e em setembro do mesmo ano são apresentados projetos eólicos para a área da Reserva. Representações do Conselho Gestor são contra a instalação das eólicas, pois não tiveram oportunidade de estudar e analisar o assunto de maneira aprofundada, ao mesmo tempo em que o órgão ambiental (Órgão Gestor) necessita de celeridade na aprovação da implantação para que os empreendedores possam concorrer em leilões de energia.

Durante a 41르 Reunião Extraordinária do Conselho Gestor, ocorrida em 10 de fevereiro de 2010 foi observado o conflito entre instituições governamentais, sejam federais, estaduais e municipais. Cabe destaque que o IDEMA, nessa reunião realizou a leitura do texto de 5 licenças concedidas para parques eólicos e dentre os parques citados na ata, alguns estão no interior da RDSEPT. Em 10 de março de 2010 foi realizada a $42^{\mathrm{a}}$ reunião extraordinária onde foram apresentados pelo Órgão Gestor os processos de licenciamento dos parques eólicos e o parque Alegria II estava na fase de instalação, já Miassaba I e II na fase de licença prévia. Conselheiros(as) relatam que o Conselho Gestor não aprovou a instalação dos parques eólicos.

$\mathrm{Na} 44^{\mathrm{a}}$ Reunião Ordinária ocorrida em 15 de outubro de 2010 é realizada cobrança pelos membros do conselho sobre informações relativas à implantação dos parques eólicos na área da RDSEPT e no seu entorno. Até o presente momento, o Conselho Gestor da unidade não aprova nenhuma implantação de empreendimento eólico. É ressaltada a inércia do IDEMA para repassar informações sobre possíveis processos de licenciamentos em andamento na área da reserva.

Durante a análise da ata da $48^{\text {a }}$ reunião extraordinária do Conselho Gestor da RDSEPT, realizada em 17 de março de 2011, fica evidente a insatisfação de vários(as) conselheiros(as) com relação ao processo de deliberação relacionado ao tema energia eólica na reserva, alguns(mas) conselheiros(as) acusaram o órgão ambiental de realizar a liberação sem o consentimento expresso do Conselho Gestor e de acordo com as leituras das atas, nenhum documento evidencia, de maneira clara, a deliberação do conselho a favor da instalação das eólicas.

$\begin{array}{llllll}\text { Caminhos de Geografia } & \text { Uberlândia-MG } & \text { v. 23, n. } 85 & \text { fev./2022 } & \text { p. 115-136 } & \text { Página } 122\end{array}$


Análise socioambiental do processo de implantação/operação de usinas eólicas na Reserva de Desenvolvimento Sustentável Estadual Ponta do Tubarão, Macau/Guamaré, Rio Grande do Norte - Brasil
Dweynny R. Filgueira Gê

Rodrigo Guimarães de Carvalho Christian Brannstrom

Adryane G. Nogueira Caetano Márcia Regina Farias da Silva

Depreende-se da ata da 49a (quadragésima nona) reunião extraordinária, do dia 26 de abril de 2011 que, no Conselho Gestor da RDSEPT, ainda permanecem conflitos quanto a autorização para implantação dos parques eólicos na área da RDSEPT, pois de acordo com conselheiros(as) não existe nenhuma documentação assinada que autoriza a implantação dos parques eólicos na região, o que existe é ata de reunião que autoriza a emissão de licenças ambientais e que, de acordo com o órgão ambiental gestor da reserva, credenciaria os empreendedores a participarem dos leilões de energia presididos pelo governo federal.

Durante a $48^{\text {a }}$ reunião ordinária, ocorrida em 09 de agosto de 2011, foi realizada apresentação de considerações sobre visita aos empreendimentos eólicos e dúvidas com relação ao posicionamento de 3 aerogeradores permearam o início da reunião, pois os(as) conselheiros(as) acreditam que esses três aerogeradores prejudiquem ainda mais o ambiente. Conselheiros(as) preocupam-se com os possíveis impactos sociais e ambientais, pois questionam as promessas de empregabilidade nos empreendimentos para pessoas da comunidade, enquanto outro conselheiro reforça que a RDSEPT vai perder muito com a implantação dos parques eólicos nas áreas onde os mesmos estão sendo alocados: em áreas de dunas móveis e de dunas fixas.

Portanto, depreende-se da ata da $48^{a}$ reunião Ordinária que os conflitos entre IDEMA (Órgão Gestor) e conselheiros (Conselho Gestor) ainda permeiam as reuniões quando o assunto é implantação e operação de energia eólica na área da RDSEPT e, além disso, é apresentado mais um conflito entre parque eólico e comunidade no que diz respeito a contratos duvidosos entre empreendedores e proprietários de terras na área da RDSEPT.

\section{Implantação/operação dos parques eólicos na RDSEPT e os impactos socioambientais}

Um dos impactos apresentados durante a pesquisa é o aterramento de áreas para implantação dos aerogeradores e para a construção de infraestrutura de suporte de acesso, por exemplo, vias de acesso aos parques eólicos e vias de acesso para os aerogeradores no interior do parque eólicos (Figura 4). O(A) entrevistado(a) R.S.L. relata que:

[...] Hoje os pescadores não têm mais acesso aos lugares onde pescavam e nós fizemos essas denúncias no Conselho Gestor, esse parque veio colocar uns acessos para os pescadores e umas placas e fotos tentando justificar e não justifica e nós fomos lá novamente, então como é uma área de duna onde há um acesso agora, com pouco tempo tem uma duna na frente. O acesso feito de piçarra, como é que os pescadores vão pisar em piçarra com um balaio de peixe nas costas, não tem condições, depois em função da ação dos ventos as dunas vão se formando, então onde estava um acesso agora já tem uma pequena duna na frente, na qual obriga ao pescador a subir e descer com um balaio entre dois homens que as circunstâncias dos acessos não permitem passar. Um pescador ou qualquer morador não podem passar nos acessos que foram construídos apesar de terem sido construídos praticamente com dinheiro público. (R.S.L., 2017). 
Análise socioambiental do processo de implantação/operação de usinas eólicas na Reserva de Desenvolvimento Sustentável Estadual Ponta do Tubarão, Macau/Guamaré, Rio Grande do Norte - Brasil
Dweynny R. Filgueira Gê

Rodrigo Guimarães de Carvalho Christian Brannstrom

Adryane G. Nogueira Caetano Márcia Regina Farias da Silva

Figura 4 - RDSEPT (RN): Parque eólico em área da RDSEPT com terraplanagem de piçarra e início de deslocamento de dunas, 2017

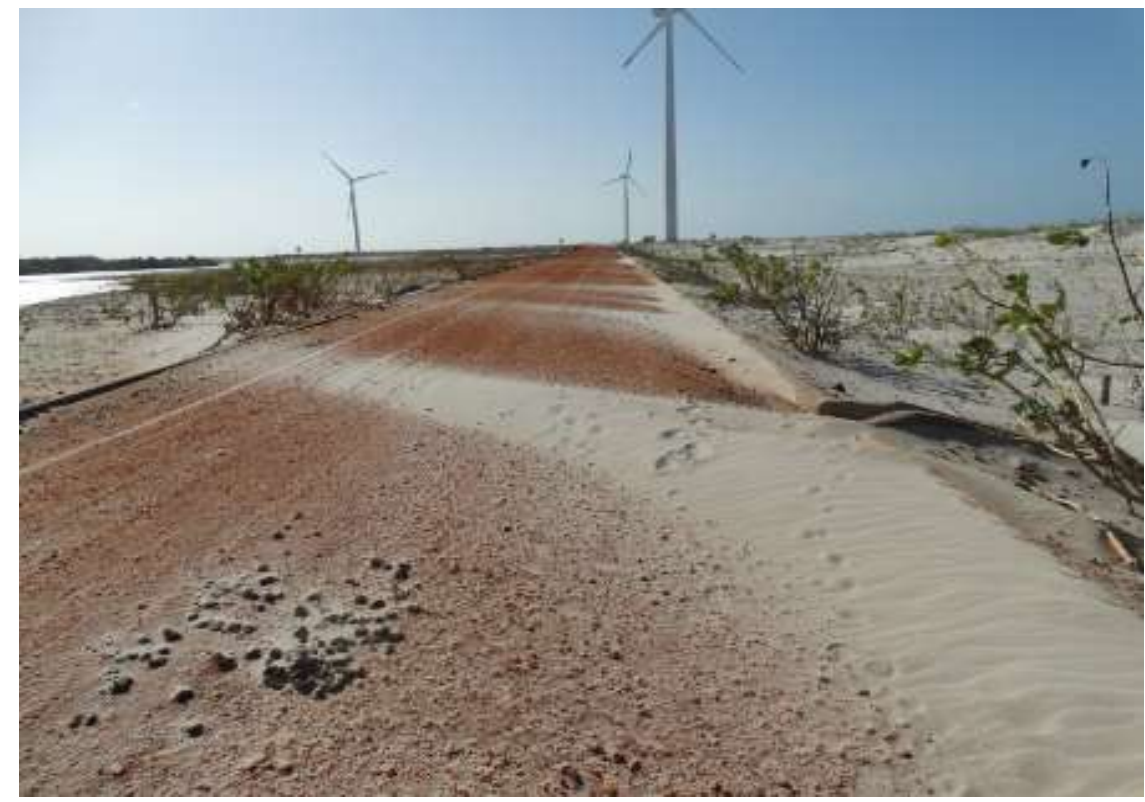

Fonte: GÊ, 2018.

Nesse contexto, relacionado aos impactos de uso da terra, Fadigas (2011) relata que existem muitas questões sobre uso da terra que devem ser consideradas no planejamento de implantação de um parque eólico. Algumas questões podem ter impactos na aceitação pública e outras podem apresentar itens relacionados a regulamentações e permissões governamentais, por exemplo: zoneamento, permissões para construção e aprovações de autoridades da aeronáutica. Dentre as principais questões Fadigas destaca: Quantidade de área potencialmente afetada pela fazenda eólica; uso não exclusivo da terra e compatibilidade; preservação rural; densidade de turbinas; área requerida por unidade de energia ou potência por unidade de área e estradas de acesso ou erosão (FADIGAS, 2011).

Em estudos realizados por Meireles (2011) no Estado do Ceará, em áreas litorâneas com presença de parques eólicos, foi possível registrar terraplenagem, aterros e cortes nas dunas, abertura de vias de acesso para cada um dos aerogeradores, desmatamento de duna fixa, movimentação de grandes volumes de areia por tratores de esteira e pás mecânicas e o soterramento de lagoas interdunares. $\mathrm{Na}$ área da RDSEPT, durante a implantação dos parques eólicos também houve impactos semelhantes aos apresentados por Meireles (2011), como a terraplanagem, construção de vias de acesso, movimentação de dunas, soterramento de lagoas.

No trabalho de Santos e Moura (2015) foi relatado que a Lagoa das Carnaúbas "foi aterrada em função da construção da eólica e construção de estradas para acesso aos mesmos, e que, diariamente, tiravam mais de 20 carros-pipa dali". O(A) entrevistado(a) R.S.L. corrobora os achados do trabalho supracitado quando diz que:

[...] As quixabeiras foram literalmente arrancadas e enterradas, houve remoção de dunas, o esgotamento da lagoa do carnaubal. Por dia, entravam de oito a quinze carros pipa para retirar água para fazer a terraplanagem, uma das poucas lagoas para a dessedentação de animais..." (R.S.L., 2017).

O(A) entrevistado(a) Q.S.M.E relata que um dos impactos causados pelos parques eólicos na RDSEPT foi a explotação da água subterrânea e o desmatamento: "Um dos prejuízos causados é no lençol freático. Teve também que ser retirado muita vegetação nativa de vários locais, tivemos uma série de prejuízos em relação a isso, mas também tivemos benefícios" (Q.S.M.E., 2017).

No documento "Considerações sobre os projetos de parques eólicos para a área da Reserva de Desenvolvimento Sustentável Estadual Ponta do Tubarão (RDSEPT) em processo de licenciamento ambiental" apresentado em plenária de reunião do Conselho Gestor no dia 29 de setembro de 2009, nas

$\begin{array}{llllll}\text { Caminhos de Geografia } & \text { Uberlândia-MG } & \text { v. 23, n. } 85 & \text { fev./2022 } & \text { p. 115-136 } & \text { Página } 124\end{array}$


Análise socioambiental do processo de implantação/operação de usinas eólicas na Reserva de Desenvolvimento Sustentável Estadual Ponta do Tubarão, Macau/Guamaré, Rio Grande do Norte - Brasil
Dweynny R. Filgueira Gê

Rodrigo Guimarães de Carvalho Christian Brannstrom Adryane G. Nogueira Caetano Márcia Regina Farias da Silva

considerações finais, os conselheiros esclarecem que a liberação do licenciamento prévio por parte do Conselho Gestor está condicionada à análise dos seguintes pontos:

\begin{abstract}
[...] Análise da perda de biodiversidade e impacto visual; impacto ambiental no que diz respeito ao movimento de terra e aterramento das lagoas e das dunas para implantação dos aerogeradores e construção de estradas para acesso aos mesmos; degradação da linha de costa, já submetida a intenso processo erosivo com movimento de terra e local de desova de tartarugas marinhas, atualmente sendo monitorada pelo IBAMA; impacto sobre o lençol freático e sobre as lagoas existentes nos tabuleiros e nas dunas; impacto na área de praia e restinga, acumulado ao processo erosivo natural da dinâmica costeira; os termos dos contratos de arrendamentos, desconhecidos pelo Conselho Gestor, que desta forma não pode responder aos questionamentos de moradores das comunidades que estão pouco informados sobre os seus direitos frente os processos de arrendamento de terras; conflito entre empreendedores e os núcleos populacionais áreas agrícolas e áreas de colocação de apetrechos e circulação de pescadores; risco de degradação do manguezal; ocupação de espaço dos pescadores na área de restinga para circulação e colocação de apetrechos de pesca; perda do acesso ao direito de ir e vir em face de situações já existentes no Estado e já identificadas por moradores locais pela fixação de placas e cercas limitando a circulação da população, antes dos procedimentos que concretizem a licença prévia ambiental para o uso da área reivindicada pelos empreendedores do Projeto Miassaba; pequena geração de emprego para as comunidades locais e por curto espaço de tempo; tendência ao aumento do índice de prostituição e do uso de drogas a partir do incremento da população local com a flutuante que virá ao lugar para a construção das bases e implantação dos aerogeradores; ameaças aos sítios arqueológicos e aos campos de quixabeiras existentes nas dunas; acentuação do problema de geração de lixo promovido pelo aumento da população flutuante; o não cumprimento das condicionantes e medidas mitigadoras, conforme experiência do Ceará; Risco potencial de problemas de saúde da população; desmatamento da vegetação da caatinga; local de aves de pouso e rota de aves migratórias; conflitos por superposição de áreas de empresas diferentes e de proprietários locais [...] (Considerações sobre projeto..., 2009).
\end{abstract}

Durante a leitura e análise das atas de reuniões do Conselho Gestor foram levantadas por conselheiros(as) e representantes das comunidades a questão relacionada a privatização dos espaços, uma vez que alguns conselheiros tentaram passar por áreas de parques eólicos e foram impedidos, por exemplo, na 50 ${ }^{\mathrm{a}}$ Reunião Ordinária, realizada em 14/12/2011, o(a) conselheiro(a) da Paróquia de Nossa Senhora da Conceição (PAMA) relatou que "o vigia the impediu de passar pelo parque e abriu o coldre da arma". O(A) representante da CJP disse que "foi barrado pelo representante da empresa eólica presente na reunião quando se aproximou do parque eólico para tirar fotos". Já um representante de comunidade relatou "em visita realizada ao parque eólico junto ao representante da PAMA, os seguranças lhes ameaçaram, mesmo sabendo que eles não estavam armados, como saberemos se o pescador que sai pela madrugada terá alguma segurança ao passar pelo parque?" (Figura 5) (Ata da $50^{\mathrm{a}}$ reunião ordinária do Conselho Gestor da RDSEPT, 2011). 
Análise socioambiental do processo de implantação/operação de usinas eólicas na Reserva de Desenvolvimento Sustentável Estadual Ponta do Tubarão, Macau/Guamaré, Rio Grande do Norte - Brasil
Dweynny R. Filgueira Gê Rodrigo Guimarães de Carvalho Christian Brannstrom Adryane G. Nogueira Caetano Márcia Regina Farias da Silva

Figura 5 - RDSEPT (RN): Placa indicativa de passagem de pescadores no interior do parque eólico Miassaba II, 2016.

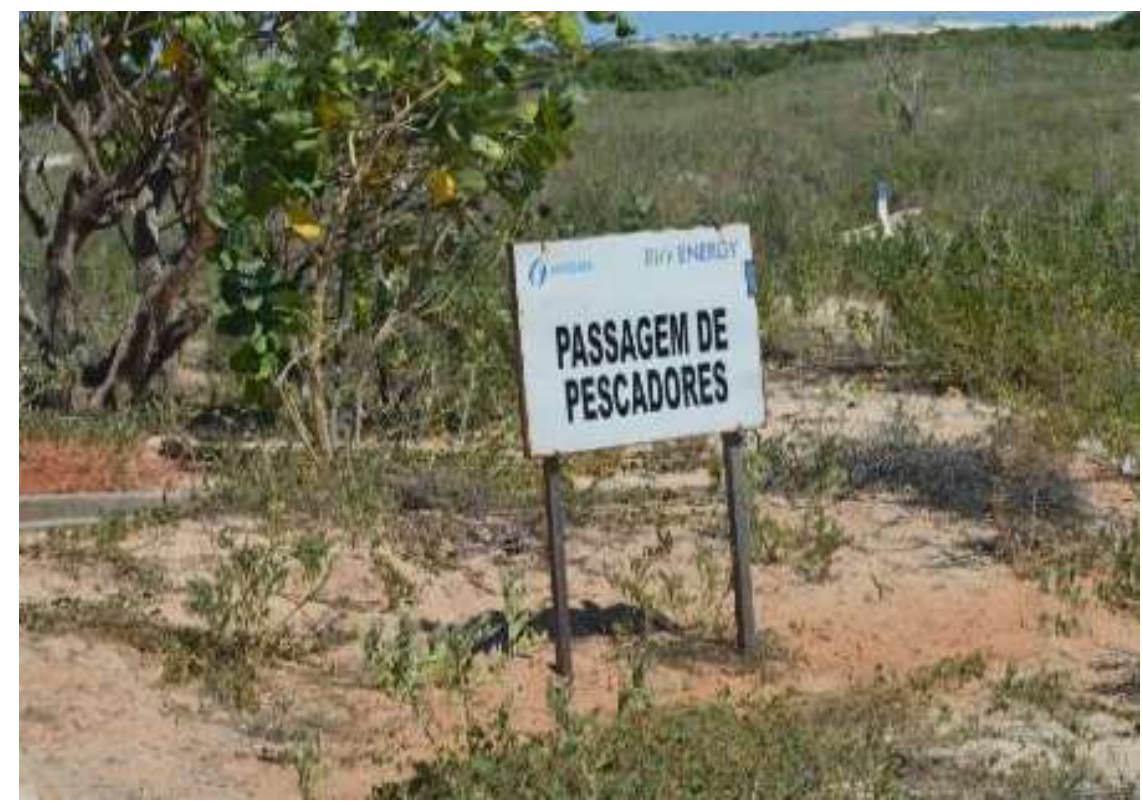

Fonte: GÊ, 2018.

Durante observação participante do seminário sobre impactos sociais e ambientais dos parques eólicos no Nordeste Brasileiro, realizado em Juazeiro, na Bahia em setembro de 2017, foram realizadas oficinas e dinâmicas que tratavam dos aspectos e impactos socioambientais de empreendimentos eólicos e foram enumerados pelas comunidades, inclusive por um grupo de moradores da RDSEPT que estava presente no evento, os principais impactos socioambientais: Danificação de estradas, controle dos territórios, apropriação do território, invasão de áreas, conflitos por divisão de terras, exploração imobiliária por políticos locais. Assim, verifica-se certa similaridade nos impactos socioambientais negativos sobre os territórios tradicionais que estão sendo reproduzidos ao longo do Nordeste brasileiro a partir da ampliação da produção de energia eólica (Figura 6A e 6B). 
Análise socioambiental do processo de implantação/operação de usinas eólicas na Reserva de Desenvolvimento Sustentável Estadual Ponta do Tubarão, Macau/Guamaré, Rio Grande do Norte - Brasil
Dweynny R. Filgueira Gê

Rodrigo Guimarães de Carvalho Christian Brannstrom

Adryane G. Nogueira Caetano Márcia Regina Farias da Silva

Figura 6 - Juazeiro (BA): (A) Apresentação de moradores da RDSEPT sobre os impactos socioambientais dos parques eólicos. (B) Visão Geral do salão durante o seminário, 2017.
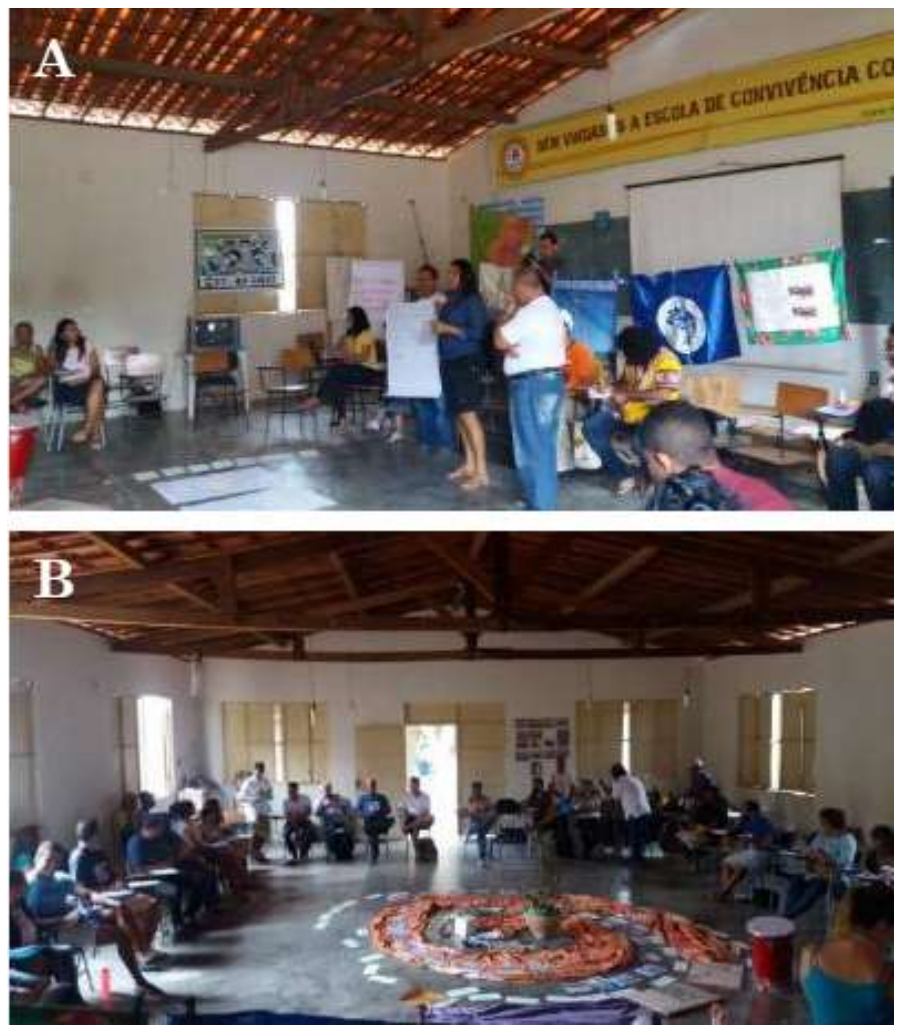

Fonte: Autor, 2017.

Em estudo realizado na costa Oeste do Ceará, na Praia do Xavier, sobre processos de planejamento de energia eólica no Nordeste do Brasil, Gorayeb et al. (2018) constataram que a comunidade próxima aos parques eólicos implantados não recebe benefício financeiro como aluguéis, royalties, serviços sociais ou comunitários, mesmo quando a construção do parque eólico soterrou lagos interdunares, impediu acesso gratuito a bens e serviços fora da comunidade devido a privatização de acessos, além de criar medo após um acidente com explosão de uma turbina eólica. Nesse sentido, o estudo apresenta conclusões que a comunidade do Xavier foi invisibilizada no processo de implantação e operação dos parques eólicos, que pode ser percebido com a não consideração do reconhecimento da comunidade do Xavier em um dos mapas apresentados no RAS ao órgão ambiental local (GORAYEB et al., 2018).

No caso da RDSEPT, as comunidades não foram invisibilizadas como no Ceará, pois a temática foi bastante discutida no Conselho Gestor da Reserva, porém não houve consenso quanto a aprovação da instalação e operação dos parques na área. Mesmo sem a aprovação formal do Conselho Gestor, os parques eólicos foram instalados na RDSEPT, ou seja, o Conselho Gestor, mesmo com caráter deliberativo e não tendo aprovado a instalação e operação das eólicas, foi desconsiderado. Ainda em análise das atas, o Órgão Gestor da unidade, o IDEMA, em diversas oportunidades tentou colocar em votação a instalação dos parques eólicos, porém não foi verificado que houve realmente votação.

$\mathrm{O}(\mathrm{A})$ entrevistado(a) R. S. L. analisa negativamente a implantação dos parques eólicos na área da RDSEPT, pois de acordo com seu discurso a implantação não foi discutida de maneira ampla com os moradores, segue relato:

[...] primeiro porque ele [parque eólico] não foi discutido começou a faltar com respeito a reserva, ao conselho gestor e aos moradores, pois ele não foi dialogado, depois teve diversos crimes ambientais, passaram dos limites quando se instalou em áreas que não deveria, hoje os pescadores não tem mais acesso aos lugares onde pescavam e nós fizemos essas denúncias no conselho gestor, esse parque veio colocar uns acessos para os pescadores e umas placas e fotos tentando justificar e não justifica e nós fomos lá novamente, então como é uma área de duna onde há um acesso agora, com pouco tempo tem uma duna na frente.

$\begin{array}{lllll}\text { Caminhos de Geografia } & \text { Uberlândia-MG } & \text { v. 23, n. } 85 & \text { fev./2022 } & \text { p. 115-136 Página } 127\end{array}$


Análise socioambiental do processo de implantação/operação de usinas eólicas na Reserva de Desenvolvimento Sustentável Estadual Ponta do Tubarão, Macau/Guamaré, Rio Grande do Norte - Brasil
Dweynny R. Filgueira Gê

Rodrigo Guimarães de Carvalho Christian Brannstrom

Adryane G. Nogueira Caetano Márcia Regina Farias da Silva

Em pesquisa realizada por Mendes et al., (2015) também foi constatada a privatização de áreas comuns, através do impedimento de acesso a determinadas áreas, bloqueio da utilização de lazer e pesca em lagoas interdunares da área.

Nesse contexto, estudo realizado no Norte de Portugal em 4 comunidades próximas à parques eólicos, relata que pessoas com interesses econômicos em projetos de empreendimentos eólicos tendem a apresentar melhor aceitação a esse tipo de energia (AREZES et al., 2014). De acordo Groth e Vogt (2014) em pesquisa realizada em Huron, Michigan, Estados Unidos, os fatores sociais e econômicos são mais influentes que os fatores ambientais na determinação do apoio de desenvolvimento de parques eólicos dentro de um município. Na China em Jiuquan, província de Gansu, a aceitação local da energia eólica depende principalmente dos benefícios econômicos percebidos (GUO et al., 2015).

O(a) entrevistado(a) F.G.A.J. relata que avalia positivamente a entrada das eólicas na área da Reserva quando diz que:

[...] as eólicas já seriam uma vantagem muito grande em muitas terras que era arisco e não tinha serventia nenhuma, com a implantação ajudou e vai ajudar muita gente por um bom tempo, apesar de não ser beneficiário eu fico feliz pelas pessoas que são. Os benefícios são econômicos para as famílias que é o principal para se viver (F.G.A.J., 2017)

O(A) entrevistado(a), V.M.S também apoia a implantação dos empreendimentos eólicos na Reserva, o mesmo relata que existem benefícios na implantação deste tipo de energia, reconhece que nem todas as famílias são beneficiadas, mas existe uma parte que sim, relata ainda que,

[...] no caso dos parques que se localizam entre o Mangue Seco 1 e 2 e Lagoa Doce que fazem parte da Reserva [RDSEPT], as famílias são beneficiadas financeiramente, recebem os royalties pela implantação dos parques, mas é a minoria das famílias, porque são as famílias de posses. Existe insatisfação na comunidade por parte das famílias que não são beneficiadas, mas as mesmas não são donas das terras só tiveram as terras cedidas para morar e não tem direito a receber por isso. Minha família está presente na comunidade a mais de 300 anos e é dona dessas terras, porém recebem os benefícios, já outras pessoas moram a bastante tempo, mas não são donos (V.M.S., 2017).

Em estudo realizado no México por Juárez-Hernández e León (2014) foi verificado que as comunidades localizadas no Istmo de Tehuantepec foram afetadas pela instalação de parques eólicos e os benefícios esperados não corresponderam às expectativas da população. Essa problemática contribuiu para aumentar as desigualdades e as divisões dentro das comunidades, gerando conflitos que ameaçaram a estabilidade social na região. Como alternativa para modificar o panorama encontrado no México foi incentivada a participação mais ampla e efetiva das populações afetadas pelos parques eólicos, assim é possível uma distribuição mais equitativa dos ganhos econômicos com possibilidade de mudança de percepção para os projetos (JUÁREZ-HERNÁNDEZ; LEÓN, 2014).

Nesse sentido e diante das constatações é factível a presença, além de impactos ambientais, de conflitos sociais relacionados à especulação imobiliária, perspectiva de geração de empregos para as comunidades locais, geração de renda para proprietários de terrenos, contratos duvidosos com relação ao arrendamento/aluguel de terras na área da reserva.

$\mathrm{Na}$ RDSEPT existem pessoas que são a favor da instalação da energia eólica, pois possuem pretensões de receber algum retorno financeiro advindo da instalação dos empreendimentos, porém foi verificado em entrevistas informais que existem moradores que já recebem retorno financeiro com a implantação dos parques em suas terras (Mangue Seco I e Mangue Seco II), porém esses moradores não são a favor da instalação de mais parques eólicos, pois os mesmos trouxeram impactos como a privatização de acessos, soterramento de lagoas e prejuízos para a comunidade de pescadores e comunidade em geral.

Nesse sentido, o(a) entrevistado(a) V.M.S. relata que os empreendimentos eólicos trouxeram impactos negativos para a RDSEPT como todo e qualquer empreendimento, porém existem impactos positivos que é a geração de renda para parte das famílias das comunidades. $\mathrm{O}(\mathrm{A})$ mesmo(a) é a favor da instalação de mais parque eólicos na área da RDSEPT, principalmente se os empreendimentos gerarem renda para a população e para a família. 
Análise socioambiental do processo de implantação/operação de usinas eólicas na Reserva de Desenvolvimento Sustentável Estadual Ponta do Tubarão, Macau/Guamaré, Rio Grande do Norte - Brasil
Dweynny R. Filgueira Gê Rodrigo Guimarães de Carvalho Christian Brannstrom Adryane G. Nogueira Caetano Márcia Regina Farias da Silva

O quadro abaixo apresenta os impactos socioambientais identificados durante a pesquisa do processo de instalação e operação dos parques eólicos na RDSEPT

Quadro 1- Síntese dos impactos socioambientais advindos da instalação e operação dos parques eólicos na RDSEPT

\begin{tabular}{|c|c|}
\hline Impacto socioambiental & Conflitos \\
\hline $\begin{array}{l}\text { Aterramento/terraplanagem de áreas para } \\
\text { implantação dos aerogeradores e vias de acesso }\end{array}$ & $\begin{array}{l}\text { Bloqueio de acessos utilizados pelos pescadores } \\
\text { tradicionais, ameaças aos sítios arqueológicos }\end{array}$ \\
\hline Movimentação de dunas e soterramento de lagoas & $\begin{array}{l}\text { Modificação na configuração do território } \\
\text { tradicional, impacto sobre o lençol freático, } \\
\text { impacto sobre o local de desova de tartarugas, } \\
\text { bloqueio da utilização de lazer e pesca em } \\
\text { lagoas interdunares da área }\end{array}$ \\
\hline Desmatamento de vegetação nativa & $\begin{array}{l}\text { Modificação na configuração do território } \\
\text { tradicional e perda de biodiversidade }\end{array}$ \\
\hline Processos de arrendamentos de terra & Desagregação social entre as comunidades \\
\hline $\begin{array}{l}\text { Privatização/bloqueio de terras - fixação de placas e } \\
\text { cercas limitando a circulação da população }\end{array}$ & e vir \\
\hline Impacto visual & $\begin{array}{l}\begin{array}{l}\text { Possibilidade de prejuízos para } \\
\text { comunitário }\end{array} \\
\text { co turismo } \\
\end{array}$ \\
\hline Especulação imobiliária & Conflitos pela posse de terras \\
\hline Distribuição de royalties/ Geração de renda & Conflitos entre famílias pela posse de terras \\
\hline Contratos imobiliários duvidosos & $\begin{array}{l}\text { Insegurança jurídica entre os envolvidos no } \\
\text { processo }\end{array}$ \\
\hline Geração de empregos para a comunidade local & $\begin{array}{l}\text { Expectativa de criação de muitos empregos, } \\
\text { porém após a fase de instalação, o } \\
\text { empreendimento gera poucos empregos para a } \\
\text { comunidade local }\end{array}$ \\
\hline
\end{tabular}

\section{Alternativas locacionais apropriadas para os parques eólicos}

A área da RDSEPT possui os mais diversos usos e ocupações (Figura 7) e conforme relatado existem 3 parques eólicos: Miassaba II, localizado na área de restinga, com proximidade do mangue e do mar (Figura 8A); Miassaba III, localizado em área de tabuleiro pré-litorâneo (Figura 8B) e Alegria II, que está presente em área de dunas (Figura $8 \mathrm{C}$ ). $\mathrm{O}$ parque eólico de Mangue Seco V está localizado em área do entorno da Reserva e em relevo de Tabuleiro. 
Análise socioambiental do processo de implantação/operação de usinas eólicas na Reserva de Desenvolvimento Sustentável Estadual Ponta do Tubarão, Macau/Guamaré, Rio Grande do Norte - Brasil
Dweynny R. Filgueira Gê Rodrigo Guimarães de Carvalho Christian Brannstrom Adryane G. Nogueira Caetano Márcia Regina Farias da Silva

Figura 7 - RDSEPT (RN): Usos e ocupações.

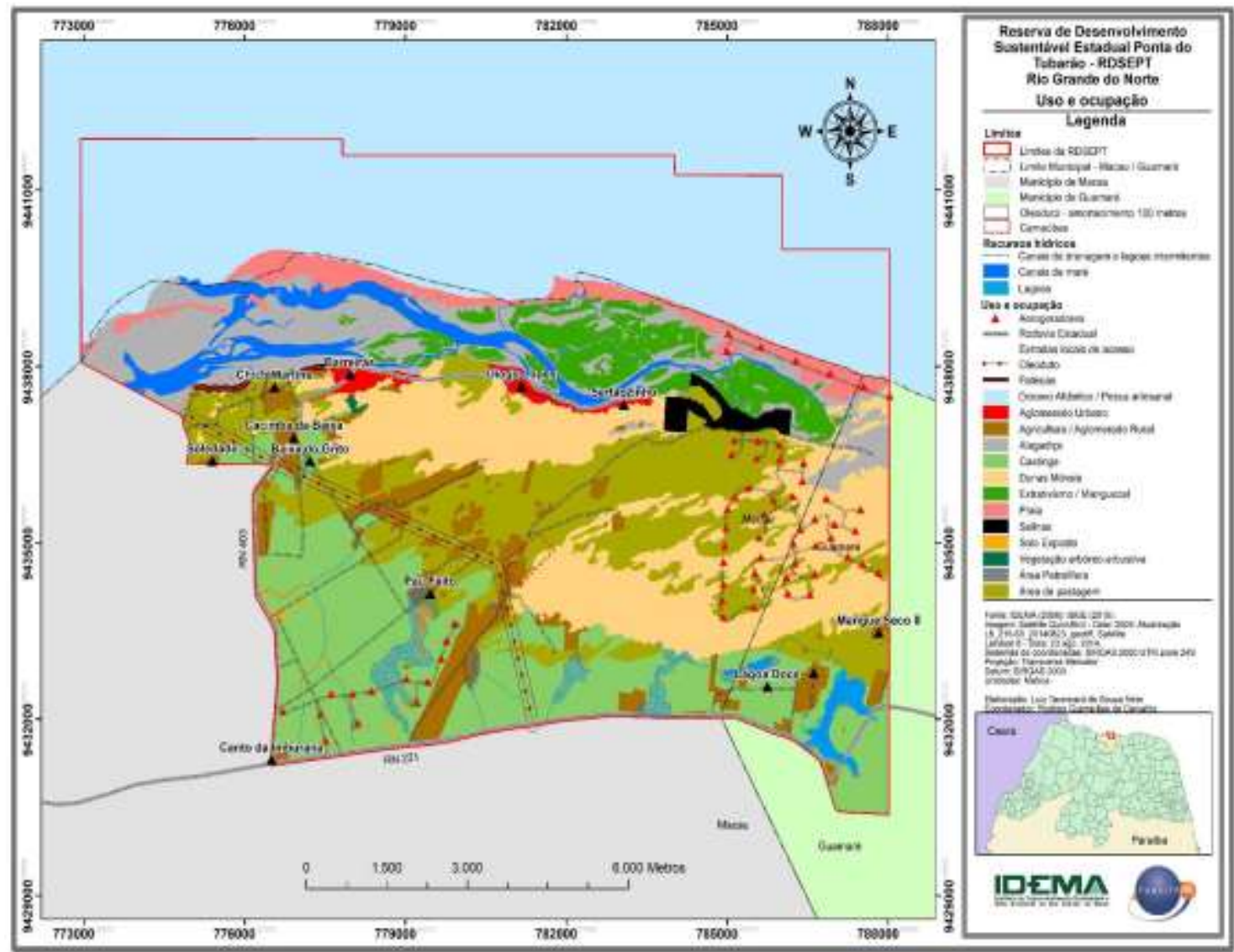

Fonte: RIO GRANDE DO NORTE, 2018. 
Análise socioambiental do processo de implantação/operação de usinas eólicas na Reserva de Desenvolvimento Sustentável Estadual Ponta do Tubarão, Macau/Guamaré, Rio Grande do Norte - Brasil
Dweynny R. Filgueira Gê Rodrigo Guimarães de Carvalho Christian Brannstrom Adryane G. Nogueira Caetano Márcia Regina Farias da Silva

Figura 8 - RDSEPT (RN): (A) Parque eólico de Miassaba II, área de restinga; (B) Parque eólico de Miassaba III, área de tabuleiro; (C) Parque eólico de Alegria II, área de dunas, 2017.
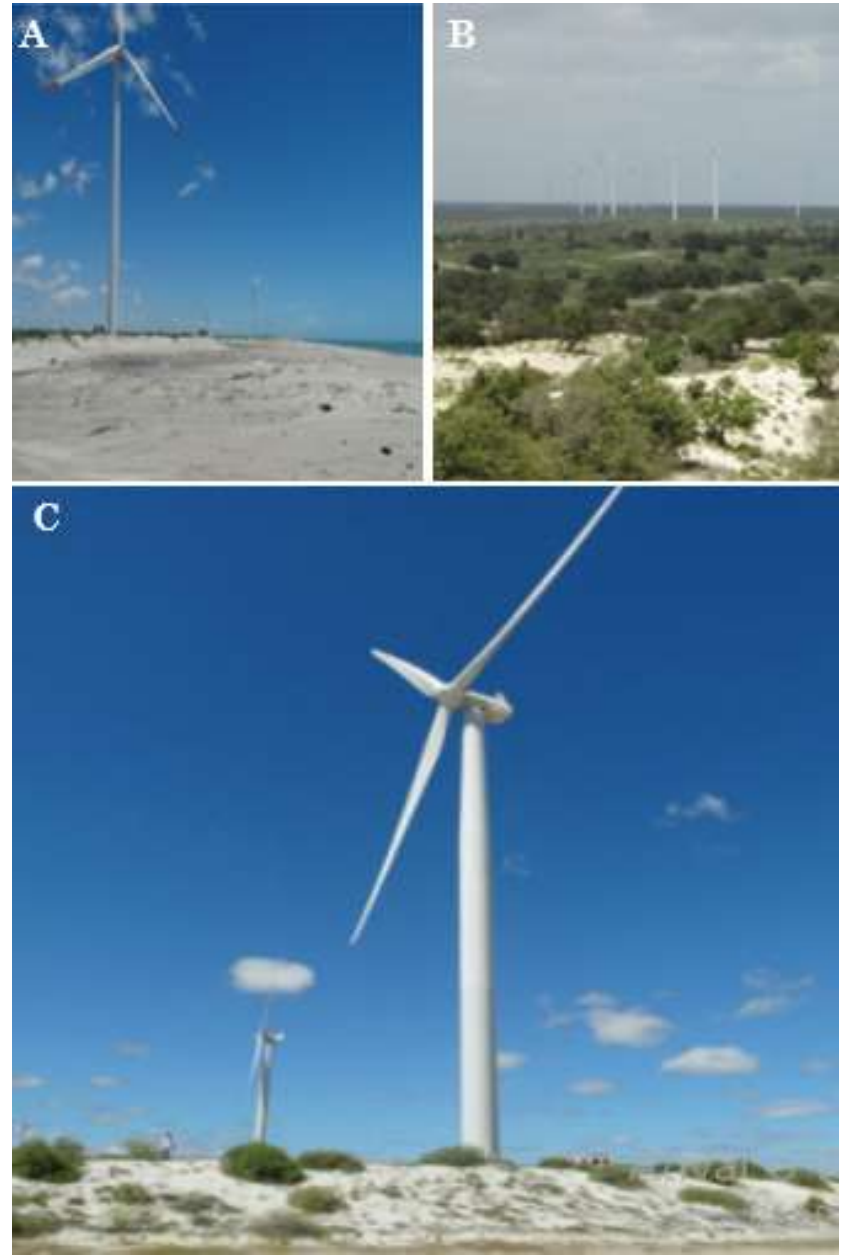

Fonte: GÊ, 2018.

Um instrumento muito conhecido na avaliação de impactos ambientais é a análise de alternativas locacionais para empreendimentos impactantes. Essa avaliação deve ocorrer primando pela geração do menor impacto possível aos meios físicos, biótico e antrópico. Nos ambientes litorâneos, estudos indicam a dinâmica ambiental e a fragilidades dos ambientes diante da possibilidade de uso e ocupação por atividades impactantes e, geralmente, indicam o tabuleiro pré-litorâneo como uma unidade ambiental mais estável do que ambientes dunares, de restinga ou de praia.

De acordo com Meireles (2011), para a instalação de 3 parques eólicos na zona costeira do município de Camocim-CE, foi definido o setor de tabuleiro pré-litorâneo, em virtude das seguintes características:

[...] Disponibilidade de vias de acesso asfaltadas e estradas carroçáveis; Possibilidade de consorciar os aerogeradores com setores amplamente utilizados para atividades agrícolas, com áreas desmatadas e vegetação secundária; Áreas disponíveis afastadas dos sistemas ambientais de preservação permanente (dunas móveis e fixas, rios, riachos e lagoas sobre o tabuleiro); Predominância dos processos geoambientais que caracterizam ambientes estáveis, desde o ponto de vista de transporte de sedimentos e atuação dos demais fluxos de matéria e energia definidos para os campos de dunas; [...] A topografia relativamente plana evidencia baixos índices de rugosidade (comparado com as dunas) o que acarretará baixos impactos nas atividades de terraplenagem, aterros e cortes para as vias de interligação entre os aerogeradores [...] (MEIRELES, 2011). 
Análise socioambiental do processo de implantação/operação de usinas eólicas na Reserva de Desenvolvimento Sustentável Estadual Ponta do Tubarão, Macau/Guamaré, Rio Grande do Norte - Brasil
Dweynny R. Filgueira Gê

Rodrigo Guimarães de Carvalho Christian Brannstrom Adryane G. Nogueira Caetano Márcia Regina Farias da Silva

De acordo com Loureiro et al. (2015) em pesquisa realizada no Município de Acaraú, o tabuleiro prélitorâneo está sendo utilizado, cada vez mais, como alternativa locacional pelas empresas de energia eólica para instalação dos empreendimentos, uma vez que estudos enumeram impactos ambientais em campos de dunas e também devido a reivindicações locais de não instalação de empreendimentos eólicos em áreas de planícies litorâneas, assim as empresas minimizam impactos ambientais já no momento da escolha da área que os parques ocuparão.

Ao avaliar o contexto de ocupação da RDSEPT pelas usinas eólicas, percebe-se que a questão das alternativas locacionais não foi levada em consideração, pois os três parques estão situados em três diferentes ambientes. No caso, existe um parque no tabuleiro pré-litorâneo que é a unidade ambiental mais estável e recomendada para esse tipo de atividade, sendo essa indicação corroborada por estudos como o de Meireles (2011) e Loureiro et al. (2015).

Outro parque está situado nas dunas móveis que é um ambiente considerado pela Resolução do Conselho Nacional do Meio Ambiente (CONAMA) n 303/2002 como área de preservação permanente e, no contexto ambiental da RDSEPT, fornece serviços ambientais essenciais às comunidades e ecossistemas associados no fornecimento de água doce que atende as necessidades sociais e regula os processos ecológicos do manguezal.

Já o terceiro parque encontra-se instalado em uma área ainda mais frágil que é a restinga, uma unidade ambiental que apresenta intensa dinâmica sedimentar de influência marinha que em pouco tempo pode apresentar processos de erosão ou acumulação de sedimentos possibilitando, assim, avanços e recuos da maré. Além disso, um importante monitoramento realizado pelo Projeto Cetáceos da Costa Branca, vinculado a Universidade do Estado do Rio Grande do Norte (UERN), indica essa área como de intensa atividade de quelônios. Também está fortemente ligada a atividade de pesca pelas comunidades da RDSEPT. É percebido, assim, que não houve um planejamento ambiental para a definição de setores a serem ocupados pelas usinas eólicas no interior da RDSEPT. Isso decorre, em partes, da ausência do Plano de Manejo e do Zoneamento Ecológico-Econômico à época, que seriam os instrumentos mais indicados para orientar os empreendedores e o órgão licenciador. Mesmo assim, os estudos ambientais prévios deveriam fazer menção às alternativas locacionais, o que não é verificado no caso em tela. Por fim, conforme discussão teórica e visitas de campo ratifica-se o tabuleiro pré-litorâneo como unidade ambiental mais estável e alternativa locacional para implantação dos parques eólicos na área da RDSEPT.

\section{CONSIDERAÇÕES FINAIS}

A pesquisa constatou que nas atas analisadas não houve, por parte do Conselho Gestor, processo de deliberação para implantação/operação de parques eólicos. O Órgão Gestor da Reserva solicitou, por vezes, aprovação da temática, porém as atas não apresentam votação indicando aprovação ou reprovação do pleito. Os conflitos entre componentes do Conselho Gestor durante as reuniões são evidentes, pois o Órgão Gestor da Reserva demonstra interesse em aprovação do tema e conselheiros(a) criticam a celeridade que o Órgão impôs na época, vislumbrando interesses econômicos e não a sustentabilidade ambiental. Nesse sentido, foi formada comissão "de energia eólica" no Conselho Gestor que elaborou relatório sobre os impactos dos parques eólicos na RDSEPT, apresentando vários casos de impactos negativos, por exemplo, à fauna, as dunas, lagoas e águas subterrâneas, bem como, aos modos de vida tradicionais com a interdição de áreas de passagem de pescadores.

Com relação aos impactos ambientais foi verificada a terraplanagem de áreas para a instalação dos aerogeradores, bem como para a construção de vias de acesso, soterramento de lagoas interdunares, retirada de vegetação nativa para a construção de parques eólicos, prejuízos ao lençol freático em virtude de interferência nas dunas, retirada de dunas móveis e terraplanagem de dunas fixas, implantação de empreendimentos eólicos em áreas ambientalmente instáveis. No que diz respeito a impactos sociais a pesquisa evidenciou a desagregação social causada entre comunidades da área da Reserva em virtude de apoio ou não, a instalação dos parques eólicos devido a benefícios econômicos; interferências em acessos tradicionais que os pescadores utilizavam para acesso à praia; contratos que foram assinados com os moradores e os mesmos não possuem conhecimento necessário para o pleno entendimento; privatização de acessos das comunidades.

Os parques eólicos Miassaba II, Alegria II e Miassaba III, estão instalados em áreas de Restinga, Dunas e Tabuleiro, respectivamente. Durante essa pesquisa, verificamos que as áreas de dunas e restinga não são as mais apropriadas para instalação dos parques devido à grande instabilidade desses ambientes, o que

$\begin{array}{lllll}\text { Caminhos de Geografia } & \text { Uberlândia-MG } & \text { v. 23, n. 85 } & \text { fev./2022 } & \text { p. 115-136 Página } 132\end{array}$


Análise socioambiental do processo de implantação/operação de usinas eólicas na Reserva de Desenvolvimento Sustentável Estadual Ponta do Tubarão, Macau/Guamaré, Rio Grande do Norte - Brasil
Dweynny R. Filgueira Gê Rodrigo Guimarães de Carvalho Christian Brannstrom Adryane G. Nogueira Caetano Márcia Regina Farias da Silva

pode ocasionar a maximização de impactos ambientais. Assim, os tabuleiros são apresentados como alternativa locacional para instalação dos empreendimentos, uma vez que são ambientes mais estáveis. No entanto, mesmo com morfologia mais adequada para instalação dos parques eólicos é necessária avaliação criteriosa dos tabuleiros, por meio da realização de estudos, diagnósticos e avaliações socioambientais, pois essas áreas são ocupadas por comunidades que dependem da utilização de recursos naturais já existentes.

Por fim, verifica-se que, mesmo se tratando de área protegida com mais de 15 anos de existência e Conselho Gestor deliberativo e atuante, a entrada das usinas eólicas não foi um processo pacífico e planejado, pois o órgão ambiental e governo estadual estavam comprometidos com a política de expansão da energia eólica no Estado. Nesse sentido, mesmo após muitas discussões no âmbito do Conselho Gestor e inexistência de aprovação para implantação/operação dos empreendimentos eólicos, o órgão ambiental estadual, juntamente com empreendedores, avançou com a instalação e operação dos parques. Portanto, o processo de implantação e operação dos parques eólicos prejudicou a relação dos(as) conselheiros(as) da Reserva junto ao Órgão Gestor, ocasionando desgaste que afeta diretamente a gestão da Reserva de Desenvolvimento Sustentável. É verificado que a inexistência de instrumentos básicos de gestão como o Plano de Manejo e o Zoneamento contribuíram para o acesso dos empreendimentos eólicos na área.

\section{AGRADECIMENTOS}

Agradecemos a Fundação Cearense de Apoio ao Desenvolvimento Científico e Tecnológico (FUNCAP), ao Conselho Nacional de Desenvolvimento Científico e Tecnológico (CNPq) e Programa de Apoio a Núcleos Emergentes (PRONEM) pelo financiamento do projeto "Análise socioambiental da implantação de parques eólicos no Nordeste: perspectivas para a sustentabilidade da geração de energia renovável no Brasil (EDITAL PRONEM/CNPq/FUNCAP e Parceria com UFC/ UFCA/ UERN/ TEXAS A\&M UNIVERSITY).

\section{REFERÊNCIAS}

ALVES-MAZZOTTI, A.J.; GEWANDSZNAJDER, F. O Método nas ciências naturais e sociais: pesquisa quantitativa e qualitativa. 2. Ed. São Paulo: Thomson, 1999. 203 p.

AMARANTE, O. A. C. do. Atlas do potencial eólico brasileiro. Brasília: MME; Rio de Janeiro: Eletrobrás, 2001.

AMARANTE, O. A. C. do. Atlas do potencial eólico do Estado do Rio Grande do Norte. Natal: Companhia Energética do Rio Grande do Norte - COSERN; Rio Grande do Norte. Iberdrola Empreendimentos do Brasil S. A. e Camargo Schumbert Engenharia Eólica, 2003.

ANEEL - Agência Nacional de Energia Elétrica. Sistema de Informações de Geração da ANEEL (SIGA) - BIG. 2020. Disponível em:

https://app.powerbi.com/view?r=eyJrljoiNic4OGYyYjQtYWM2ZC00YjlllLWJIYmEtYzdkNTQ1MTc1NiM2liwi dCI6ljQwZDZmOWI4LWVjYTctNDZhMi05MmQ0LWVhNGU5YzAxNzBIMSIsImMiOjR9. Acesso: 15 mar. 2020.

ANEEL - Agência Nacional de Energia Elétrica. Capacidade de Geração do Rio Grande do Norte. 2018. Disponível em: http://www2.aneel.gov.br/aplicacoes/ResumoEstadual/GeracaoTipoFase.asp. Acesso: 22 jan. 18.

AREZES, P. M.; Bernardo, C.A.; Ribeiro, E.; Dias, H. Implications of Wind Power Generation: Exposure to Wind Turbine Noise. Procedia - Social And Behavioral Sciences, [s.I.], v. 109, p.390-395, jan. 2014. Elsevier BV. doi: http://dx.doi.org/10.1016/j.sbspro.2013.12.478.

ARVESEN, A.; HERTWICH, E. G. Assessing the life cycle environmental impacts of wind power: A review of present knowledge and research needs. Renewable And Sustainable Energy Reviews, [s.I.], v. 16, n. 8, p.5994-6006, out. 2012. Elsevier BV. doi: http://dx.doi.org/10.1016/j.rser.2012.06.023.

BRANNSTROM, C.; GORAYEB, A.; MENDES, J. S.; LOUREIRO, C.; MEIRELES, A. J. A.; SILVA, E. V.; FREITAS, A. L. R.; OLIVEIRA, R. F. Is Brazilian wind power development sustainable? Insights from a 
Análise socioambiental do processo de implantação/operação de usinas eólicas na Reserva de Desenvolvimento Sustentável Estadual Ponta do Tubarão, Macau/Guamaré, Rio Grande do Norte - Brasil
Dweynny R. Filgueira Gê Rodrigo Guimarães de Carvalho Christian Brannstrom Adryane G. Nogueira Caetano Márcia Regina Farias da Silva

review of conflicts in Ceará state. Renewable And Sustainable Energy Reviews, [s.I.], v. 67, p. 62-71, jan. 2017. Elsevier BV. doi: http://dx.doi.org/10.1016/j.rser.2016.08.047.

BRANNSTROM, C.; GORAYEB, A. SOUZA, W. F.; LEITE, N. S.; CHAVES, L. O. CARVALHO, R. G.; GÊ, D. R. F. Perspectivas geográficas nas transformações do litoral brasileiro pela energia eólica. Revista Brasileira de Geografia. v.63, n.1, p. 3-28, jan./jun 2018. doi: https://doi.org/10.21579/issn.2526$03752018 \mathrm{n} 1 \mathrm{p} 3-28$.

CEPEL - Centro de Pesquisas de Energia Elétrica. Atlas do Potencial Eólico Brasileiro: simulações 2013. Rio de Janeiro, 2017. 52 p. Disponível em: < http://www.observatoriodaenergiaeolica.ufc.br/wpcontent/uploads/2019/07/NovoAtlasdoPotencialEolico BrasileiroSIM 2013-compressed.pdf>. Acesso em: 01 jun. 2020.

DAI, K.; BERGOT, A.; LIANG, C.; XIANG, WN.; HUANG, Z. Environmental issues associated with wind energy - A review. Renewable Energy, [s.I.], v. 75, p.911-921, mar. 2015. Elsevier BV. doi: http://dx.doi.org/10.1016/i.renene.2014.10.074.

DANTAS, E.J.A.; ROSA, L.P.; SILVA, N.F.; PEREIRA, M.G. Wind Power on the Brazilian Northeast Coast, from the Whiff of Hope to Turbulent Convergence: the case of the galinhos wind farms. Sustainability, [s.l.], v. 11, n. 14, p. 3802, 11 jul. 2019. MDPI AG. doi: http://dx.doi.org/10.3390/su11143802.

DOIS A ENGENHARIA (NATAL). Parque eólico Miassaba III. 2018. Disponível em: < http://www.doisa.com/portfolio/parque-eolico-miassaba-iii>. Acesso em: 22 jan. 2018.

FADIGAS, E. A. F. A. Energia eólica e meio ambiente. In: FADIGAS, Eliane A. Faria Amaral (Org.). Energia eólica. Barueri: Manole, 2011. P. 253-278. (Sustentabilidade).

FAIRHEAD, J. LEACH, M. SCOONES, I. Green Grabbing: a new appropriation of nature? The Journal of Peasant Studies. Vol. 39, No. 2, April 2012, 237-261. doi:

http://dx.doi.org/10.1080/03066150.2012.671770.

FRATE, C. A.; BRANNSTROM, C.; MORAIS, M. V. G.; CALDEIRA-PIRES, A. A. Procedural and distributive justice inform subjectivity regarding wind power: a case from Rio Grande do Norte, Brazil. Energy Policy, [s.I.], v. 132, p. 185-195, set. 2019. Elsevier BV. doi: http://dx.doi.org/10.1016/j.enpol.2019.05.027.

FREITAS, M. M. Avaliação de riscos geológicos no planejamento energético eólico no Rio Grande do Norte, Brasil. Mercator, Fortaleza, v. 15, n. 1, p.117-129, mar. 2016. doi: https://doi.org/10.4215/RM2016.1501.0009.

GÊ, D. R. F. Unidades de conservação e expansão de usinas eólicas no Rio Grande do Norte: o caso da reserva de desenvolvimento sustentável estadual ponta do tubarão. 2018. 139 f. Dissertação (Mestrado) - Curso de Ciências Naturais, Universidade do Estado do Rio Grande do Norte, Mossoró, 2018.

GÊ, D. R. F.; CARVALHO, R. G. de; SILVA, M. R. F. da. Unidades de conservação e energia eólica no Rio Grande do Norte: o caso da reserva de desenvolvimento sustentável estadual ponta do tubarão. In: Gorayeb, A. et al. (org.). Impactos socioambientais da implantação dos parques de energia eólica no Brasil. Fortaleza: Edições UFC, 2019. P. 251-262.

GEIBLER, G.; KÖPPEL, J.; GUNTHER, P. Wind energy and environmental assessments - A hard look at two forerunners' approaches: Germany and the United States. Renewable Energy, [s.I.], v. 51, p.71-78, mar. 2013. Elsevier BV. doi: http://dx.doi.org/10.1016/..renene.2012.08.083.

GIL, A. C. Métodos e técnicas de pesquisa social. 5.ed. São Paulo: Atlas, 1999.

GORAYEB, A.; BRANNSTROM, C.; MEIRELES, A. J. A.; MENDES, J. S. Wind power gone bad: Critiquing wind power planning processes in northeastern Brazil. Energy Research \& Social Science, [s.l.], v. 40, p.82-88, jun. 2018. Elsevier BV. doi: http://dx.doi.org/10.1016/i.erss.2017.11.027.

GROTH, T. M.; VOGT, C. A. Rural wind farm development: Social, environmental and economic features ocioambie to local ocioambie. Renewable Energy, [s.I.], v. 63, p.1-8, mar. 2014. Elsevier BV. doi: http://dx.doi.org/10.1016/..renene.2013.08.035. 
Análise socioambiental do processo de implantação/operação de usinas eólicas na Reserva de Desenvolvimento Sustentável Estadual Ponta do Tubarão, Macau/Guamaré, Rio Grande do Norte - Brasil
Dweynny R. Filgueira Gê Rodrigo Guimarães de Carvalho Christian Brannstrom Adryane G. Nogueira Caetano Márcia Regina Farias da Silva

GUO, Y.; RU, P.; SU, J.; ANADON, L. D. Not in my backyard, but not far away from me: Local acceptance of wind power in China. Energy, [s.I.], v. 82, p.722-733, mar. 2015. Elsevier BV. doi: http://dx.doi.org/10.1016/i.energy.2015.01.082.

GWEC. Global Wind Energy Council. Global Wind Report, 2019. Disponível em: <https://gwec.net/globalwind-report-2019/.pdf>. Acesso 22 abril. 2020.

HOFSTAETTER, M.; PESSOA, Z. S. Energia Eólica: um novo debate, entre defesas e contradições. In: VII Jornada Internacional de Políticas Públicas, 2015, São Luís, Maranhão.

IEA-International Energy Agency. Energy Atlas, Electricity Information book, 2017. Disponível em: http://energyatlas.iea.org/\#!/tellmap/-1118783123. Acesso em: 22 abril 2020.

JUÁREZ-HERNÁNDEZ, S.; LEÓN, G. Energía eólica em el istmo de Tehuantepec: desarrollo, actores y oposición social. Revista Problemas del Desarrollo, México, v. 45, n. 178, p.139-162, jul. 2014. doi: https://doi.org/10.1016/S0301-7036(14)70879-X.

KALDELLIS, J.K.; APOSTOLOU, D.; KAPSALI, M.; KONDILI, E. Environmental and social footprint of offshore wind energy. Comparison with onshore counterpart. Renewable Energy, [s.I.], v. 92, p.543-556, jul. 2016. Elsevier BV. doi: http://dx.doi.org/10.1016/j.renene.2016.02.018.

LAKATOS, E. M.; MARCONI, M. A. Fundamentos metodologia científica. 4.ed. São Paulo: Atlas, 2001.

LOUREIRO, C. V.; GORAYEB, A.; BRANNSTROM, C. Implantação de energia eólica e estimativa das perdas ambientais em um setor do litoral Oeste do Ceará, Brasil. Geosaberes, Fortaleza, v. 6, n. especial 1, p.28-38, outubro. 2015. Disponível em: < http://www.geosaberes.ufc.br/geosaberes/article/view/361>.

MAMERI, S. F. Comunidades Tradicionais em Áreas Protegidas: Convergências e lacunas da política urbana e ambiental na Reserva de Desenvolvimento Sustentável Estadual Ponta do Tubarão/RN. 2011. 159 f. Dissertação (Mestrado) - Curso de Arquitetura e Urbanismo, Universidade Federal do Rio Grande do Norte, Natal, 2011.

MARTINS, F. R.; GUARNIERI, R. A.; PEREIRA, E. B. O aproveitamento da energia eólica. Revista Brasileira de Ensino de Física, v. 30, n. 1, 1304, nov. 2008. doi: https://doi.org/10.1590/S010247442008000100005

MATTOS, P. P.; KONIG, A.; FREIRE, F. A. M.; ALOUFA, M. A. I. Etnoconhecimento e percepção dos povos pesqueiros da Reserva Ponta do Tubarão acerca do ecossistema manguezal. Revista Brasileira de Biociências, Porto Alegre, v. 10, n. 4, p.481-489, dez. 2012. Disponível em: < http://www.ufrgs.br/seerbio/ojs/index.php/rbb/article/viewFile/2102/1167>.

MEIRELES, A. J. A. Danos socioambientais originados pelas usinas eólicas nos campos de dunas do Nordeste brasileiro e critérios para definição de alternativas locacionais. Confins, [s.I.], n. 11, 27 mar. 2011. OpenEdition. doi: http://dx.doi.org/10.4000/confins.6970.

MENDES, J. DE S.; GORAYEB, A.; BRANNSTROM, C. Diagnóstico participativo e cartografia social aplicados aos estudos de impactos das usinas eólicas no litoral do Ceará: o caso da praia de Xavier, Camocim. Geosaberes, Fortaleza, v. 6, n. 3, p. 243 - 254, july 2015. ISSN 2178-0463. Disponível em : < http://www.geosaberes.ufc.br/geosaberes/article/view/510>.

MOREIRA, R. N.; VIDAL, F. A. B.; VIANA, A. F.; OLIVEIRA, D. A. B. Energia eólica no quintal da nossa casa?! Percepção ambiental dos impactos socioambientais na instalação e operação de uma usina na comunidade de sítio do Cumbe em Aracati-CE. Revista de Gestão Ambiental e Sustentabilidade, [s.I.], v. 2, n. 1, p. 45-73, 1 jun. 2013. University Nove de Julho. doi: http://dx.doi.org/10.5585/geas.v2i1.39.

NOBRE, I. M. Revelando os modos de vida da Ponta do Tubarão. 2005. 260 f. Tese (Doutorado) Curso Ciências Sociais, Universidade Federal do Rio Grande do Norte, Natal, 2005.

RIO GRANDE DO NORTE. Carvalho, R. G. (coord.). Plano de Manejo da Reserva de Desenvolvimento Sustentável Estadual Ponta do Tubarão. Universidade do Estado do Rio Grande do Norte. Natal, 2018.

SANTOS, A. C. R.; MOURA, F. C. C. Impactos socioambientais causados pelos aerogeradores na Reserva de Desenvolvimento Sustentável Estadual Ponta do Tubarão (RDSEPT). In: Camacho, R. G. V. et al. (Org.). Educação e Sustentabilidade em unidades de conservação. Mossoró: Edições UERN, 2015. P. 248-264. 
Análise socioambiental do processo de implantação/operação de usinas eólicas na Reserva de Desenvolvimento Sustentável Estadual Ponta do Tubarão, Macau/Guamaré, Rio Grande do Norte - Brasil
Dweynny R. Filgueira Gê Rodrigo Guimarães de Carvalho Christian Brannstrom

Adryane G. Nogueira Caetano Márcia Regina Farias da Silva

THE WIND POWER (França). Alegria II (Brasil). 2017a. Disponível em: < https://www.thewindpower.net/windfarm es 17500 alegria-ii.php>. Acesso em: 22 jan. 2018.

THE WIND POWER (França). Miassaba II (Brasil). 2017b. Disponível em: < https://www.thewindpower.net/windfarm es 4123 miassaba-ii.php>. Acesso em: 22 jan. 2018.

Recebido em: 21/09/2020

Aceito para publicação em: 15/03/2021 